\title{
LA PRODUCCION AGRARIA Y EL CONSUMO ESPAÑOL EN EL SIGLO XIX*
}

JAMES SIMPSON

Universidad Complutense

\section{INTRODUCCION}

Las dificultades que existian para determinar la producción agraria a nivel nacional, en el siglo xIx, son bien conocidas. La poca fiabilidad del diezmo en muchas zonas del país después de la Guerra de la Independencia, y la falta de un catastro o de buenas informaciones del tamaño de la superficie cultivada, hicieron casi imposible la tarea de los economistas y agrónomos durante la mavor parte del siglo xIx para calcular cifras razonables de la producción. Por tanto, será muy difícil obtener hoy día un índice, bien con datos de los archivos o bien por métodos estadísticos indirectos, que muestre las fluctuaciones a corto plazo y que tenga un nivel de fiabilidad suficientemente alto para ser útil. No obstante, para obtener una aproximación de las transformaciones de la economía española a largo plazo, es necesario saber algo de los ritmos de cambio en el sector agrario. El historiador tiene dos posibilidades: utilizar fuentes como las estimaciones de producción que se encuentran en el Censo de Frutos y Manufacturas o las de la Junta Consultiva Agronómica (JCA) y Sotilla, o recurrir a otros indicadores, como los cambios en la renta per capita o el consumo de alimentos, como aproximaciones.

Este trabajo empieza con una breve crítica de las fuentes más importantes para calcular la producción y consumo durante el siglo xix, y concluye que éstas no son suficientemente fiables para determinar cambios a largo plazo. En la segunda parte examinamos la dieta española en 1900, y comprobamos que la cantidad de calorías consumidas no fue alta, y que un amplio por-

* Quiero agradecer al Banco de España la concesión de una beca que me permitió realizar el primer borrador de este artículo dentro del proyecto «Producción, productividad y renta de las economias de Europa occidental, 1789-1956». Igualmente, quiero agradecer a los asistentes al XII Simposio de Análisis Económico y al III Seminario de Historia Económica Cuantitativa los comentarios que me hicieron. F. Comin, J. Cuenca, R. Dobado, P. Martín Aceña, L. Prados, G. Tortella, S. Zapata y un lector anónimo hicieron valiosas sugerencias en distintos momentos de la elaboración de este artículo, que también les agradezco. Los errores y opiniones son, por supuesto, responsabilidad del autor. 
centaje fue obtenido de productos básicos, como el pan o las patatas. Impresiones optimistas sobre el desarrollo de la agricultura en la segunda mitad del siglo (el aumento en la renta per capita y el despegue de las exportaciones) son contrastadas con opiniones menos optimistas (rendimientos decrecientes en la agricultura y las crisis de subsistencia). Por último, discutimos el reciente cálculo de la producción agraria de Prados de la Escosura, y observamos que sus resultados son demasiado altos, y que la productividad de la mano de obra y la tierra cambió poco durante el siglo xix.

\section{LAS FUENTES PARA CALCULAR LA PRODUCCION AGRARIA}

\subsection{7-1803 y el «Censo de Frutos y Manufacturas»}

El Censo de Frutos, elaborado en 1799, fue de hecho el segundo esfuerzo de la Corona para hacer una recopilación anual de la producción agrícola. La Real Orden del 2 de febrero de 1787 obligaba a todos los intendentes a remitir anualmente a «la Secretaría de Estado y del Despacho Universal de Hacienda de España una razón circunstanciada de la cantidad, precio y consumo de los frutos y manufacturas de sus Provincias»'. El resultado es que, entre 1787 y 1799 , existen cifras de producción de los principales productos agrícolas, de varias provincias y de diferentes años. Se repitieron las órdenes en 1799, debido a que varias de las provincias prefirieron ignorar la Orden o enviaron cifras poco fiables. Según el sumario de 1803, compilado por Juan Polo y Catalina, la Orden de 1799 tampoco fue seguida por todos:

«La poca exâctitud que se encuentra en muchos de los estados remitidos por los Intendentes; las faltas que se han notado en algunos, y la obscuridad que han presentado otros, hiciéron demasiadamente trabajosa la redaccion de este Censo, el qual carece para ello de la certeza que desearán los que le leyeren» ${ }^{2}$.

Fontana criticó duramente casi todos los aspectos del Censo, con la excepción de las cosechas de cereales, de las cuales él dice que fueron «calculadas a partir de los diezmos» ${ }^{3}$. No obstante, según Pinilla, otro adversario

' Polo y Catalina (1803), sin paginación.

2 Polo y Catalina (1803).

${ }^{3}$ Fontana Lázaro (1967), p. 61. 
del Censo, los diezmos fueron inadecuados para construir una cifra de la producción cereal porque

\begin{abstract}
«... se hizo en esta parte por el resultado de las tazmías o declaraciones que hacían los cosecheros para el adeudo del diezmo; pero no se tuvo presente que estos documentos no comprendían los que eran de privativa percepción de los párrocos y otros partícipes, ni tampoco que en la época en que se dieron había muchas corporaciones y fincas exentas de diezmar" ${ }^{4}$.
\end{abstract}

Una segunda dificultad de la fuente es la necesidad de determinar si 1799 fue un año representante o no de la época. Para el período que va de 1787 a 1803, existe suficiente información para calcular a nivel nacional cifras de la producción del trigo y centeno para cinco años, cebada y maíz (con panizo) para cuatro, y avena para tres. Los resultados se muestran en el cuadro 1.

\title{
CUADRO 1
}

Estimación de la producción nacional de cereales

(Miles de fanegas)

\begin{tabular}{|c|c|c|c|c|c|}
\hline & 1787 & 1791 & 1797 & 1799 & 1803 \\
\hline $\begin{array}{lllllllll}\text { Trigo } & \ldots & \ldots & \ldots & \ldots & \ldots & \ldots & \ldots & \ldots \\
\text { Centeno } & \ldots & \ldots & \ldots & \ldots & \ldots & \ldots & \ldots & \ldots \\
\text { Cebada } & \ldots & \ldots & \ldots & \ldots & \ldots & \ldots & \ldots \\
\text { Maiz y } & \text { panizo } & \ldots & \ldots & \ldots & \ldots & \ldots \\
\text { Avena } & \ldots & \ldots & \ldots & \ldots & \ldots & \ldots & \ldots \\
\text { Arroz } & \ldots & \ldots & \ldots & \ldots & \ldots & \ldots & \ldots & \ldots \\
\text { Otros } & \ldots & \ldots & \ldots & \ldots & \ldots & \ldots & \ldots & \ldots \\
\end{array}$ & $\begin{array}{r}30.095 \\
6.584 \\
3.160\end{array}$ & $\begin{array}{r}34.111 \\
10.310 \\
15.651 \\
4.571 \\
3.960\end{array}$ & $\begin{array}{r}31.975 \\
7.828 \\
14.607 \\
4.504 \\
3.197\end{array}$ & $\begin{array}{r}33.136 \\
7.949 \\
16.103 \\
4.320 \\
3.132 \\
507 \\
592\end{array}$ & $\begin{array}{l}30.716 \\
10.167 \\
14.895\end{array}$ \\
\hline
\end{tabular}

* «Otros cereales» incluyen escaña, comuna, tranquillón, etc.

Notas: Para los años 1791, 1797 y 1799, las fuentes dan cifras a niveles provinciales. Cuando en una provincia falta la cosecha para un año, la media de las dos cosechas de los otros años ha sido utilizada. Cuando solamente hay datos para un año, la misma cifra para las otras dos fechas está usada. En 1799, la cifra de centeno en Soria ha sido reducida de 2.100 a 210 , y la cifra en Toledo, de 1.470 a 147.

Fuentes: 1787: Canga Argüelles (1833-34), tomo 2, p. 532. Las cifras son bajas, en opinión de Canga Argüelles. 1791: AHN, Consejos, leg. 4174; citado en Anes (1970), p. 148. 1797: AHN, Consejos, leg. 1345, f. 30; citado en Anes (1970), p. 149. 1799: Polo y Catalina (1803), cuadro 1. 1803: Moreau de Jonnes (1835), p. 124.

\footnotetext{
+ Fontana Lázaro (1967), p. 61.
} 
La impresión inmediata es de una relativa estabilidad en la producción de trigo, con una media de 1.384 mil toneladas, y una desviación estándar de 64,2 . Este nivel de estabilidad en las cifras, más que satisfacernos, debe preocuparnos sobre la exactitud de la fuente, ya que en aquella época las cosechas estaban sometidas a grandes fluctuaciones. En España, entre 1919 y 1935, un período para el cual podríamos estar más seguros de la exactitud de las estadísticas, la media fue de 3.997 mil toneladas, y la desviación estándar, 503,2. Además, los índices de precios de trigo compilados por Anes muestran fuertes fluctuaciones a finales del siglo xvinl y a principios del xIX, una parte de las cuales se originaron por cambios en la oferta de cereales 5 .

Los estudios de Calomarde e Ignacio de Asso sobre la provincia de Ara. gón proporcionan más información sobre la manera de calcular las cifras en esta época y las fluctuaciones anuales de las cosechas. Estos dos coetáneos criticaron como inadecuadas las listas de producción que los corregidores remitían anualmente a los intendentes. La cifra de 1787 fue dada a Ignacio de Asso por el intendente, Ximénez Navarro, y la cosecha de trigo en este año fue «abundantísima en tanto grado, que en Abril de 1788 no excedió el precio de 40 reales por cahíz» ${ }^{6}$. Sin embargo, la cifra de 1.039 .913 cahíces (3.466.377 fanegas) para el año era demasiado baja por cuestiones de fraude, e Ignacio de Asso escribió que

«algunas personas bien instruidas en las cosechas de sus respectivos distritos me han asegurado, que en los manifiestos destinados para la Intendencia, es mui frecuente rebaxar una quarta parte del producto verdadero" ?

Para determinar el nivel del error, Calomarde hizo en la provincia de Aragón, para el quinquenio 1793-1797, una comparación entre las cifras de los corregidores/intendentes y las "que se manifiestan por las tablas diezmarias, y noticias de lo que se ha cogido en las tierras que por privilegio no han pagado diezmo" ${ }^{8}$. Los cálculos de los corregidores/intendentes indican una cosecha media de 2.895 .000 fanegas, que representa solamente el 60 por 100 de la cosecha de 4.870 .000 fanegas, según Calomarde. Por supuesto, no sabemos hasta qué punto el cálculo de Calomarde es representativo no solamente en Aragón, sino también para el resto del país.

'Anes (1966), pp. 69-102.

- I. de Asso (1798), pp. 189 y 192

I. de Asso (1798), p. 193.

8 Calomarde (1800), pp. 17-18. 


\section{CUADRO 2}

Producción de trigo en la provincia de Aragón, 1787-1799

\begin{tabular}{|c|c|c|c|c|}
\hline & (1) & (2) & (3) & \\
\hline $\begin{array}{llllllllll}1787 & \ldots & \ldots & \ldots & \ldots & \ldots & \ldots & \ldots & \ldots & \ldots \\
1791 & \ldots & \ldots & \ldots & \ldots & \ldots & \ldots & \ldots & \ldots & \ldots \\
1792 & \ldots & \ldots & \ldots & \ldots & \ldots & \ldots & \ldots & \ldots & \ldots \\
1793 & \ldots & \ldots & \ldots & \ldots & \ldots & \ldots & \ldots & \ldots & \ldots \\
1794 & \ldots & \ldots & \ldots & \ldots & \ldots & \ldots & \ldots & \ldots & \ldots \\
1795 & \ldots & \ldots & \ldots & \ldots & \ldots & \ldots & \ldots & \ldots & \ldots \\
1796 & \ldots & \ldots & \ldots & \ldots & \ldots & \ldots & \ldots & \ldots & \ldots \\
1797 & \ldots & \ldots & \ldots & \ldots & \ldots & \ldots & \ldots & \ldots & \ldots \\
1798 & \ldots & \ldots & \ldots & \ldots & \ldots & \ldots & \ldots & \ldots & \ldots \\
1799 & \ldots & \ldots & \ldots & \ldots & \ldots & \ldots & \ldots & \ldots & \ldots \\
1793-97 & \ldots & \ldots & \ldots & \ldots & \ldots & \ldots & \ldots & \ldots \\
179 & \ldots & \ldots & \ldots & \ldots\end{array}$ & $\begin{array}{l}3.466 \\
3.138\end{array}$ & $\begin{array}{r}\text { Media } \\
2.749 \\
\\
3.478\end{array}$ & $\begin{array}{l}4.932 \\
4.745 \\
5.015 \\
4.041 \\
5.616 \\
6.112\end{array}$ & $\begin{array}{r}\text { Media } \\
4.683\end{array}$ \\
\hline
\end{tabular}

Nota: En miles de fanegas castellanas: 1 cahice $=3,33$ fanegas.

Fuentes: (1) 1787: Ignacio de Asso (1798), p. 189; 1791 y 1797: Anes (1970), pp. 148149; 1799: Censo de Frutos.

(2) Calomarde: Intendentes/Corregidores.

(3) Calomarde: Diezmos y «noticias de lo que se ha cogido en las tierras que por privilegio no han pagado diezmom.

\subsection{7}

Las dificultades de utilizar las cifras de la producción agraria, ofrecidas por la Junta General de Estadística de 1857, son muy conocidas. Aparte de los problemas de ocultación, la cosecha fue una de las peores del siglo y. por tanto, no era representativa de la época. Por contraste, el intento de Fermín Caballero de corregir el cálculo de la JGE es muy exagerado ${ }^{9}$. Ninguno de los dos podía facilitar pistas seguras sobre el desarrollo de la agricultura durante el siglo pasado.

\section{3. $1880-1900$}

El último grupo de estadísticas son las que empezaron a salir a finales del siglo xix. Como son series de producción anual, las complicaciones presentadas por las fluctuaciones en las cosechas por causa del clima ya no existen. Ahora era el agrónomo provincial el que tenía la responsabilidad

\footnotetext{
Tortella Casares (1985), pp. 73-82; véase, también, Sanz (1981).
} 
de recopilar las cifras y, dados los pocos recursos de que disponía, no es sorprendente que los primeros intentos tuvieran muchas veces una inexactitud bastante grande. Parece que el método elegido era hacer una estimación de la superficie cultivada, quizá usando los Amillaramientos, y luego se calculaba un rendimiento medio por hectárea en la provincia cada año. No obstante, siguen apareciendo cantidad de errores en las fuentes y cambios bruscos en las cifras, sin ninguna explicación. Las cifras de producción en la década de 1800 no son fiables en muchas provincias. Para la última década del siglo XIX, la fuente normalmente utilizada por los historiadores para conocer la superficie cultivada y la producción es E. de la Sotilla ${ }^{10}$. Las cifras de Sotilla muestran una recuperación rápida de la superficie cultivada de trigo después de 1891: desde unos 2,7 millones de hectáreas en 1891 a 3,4 millones en 1892, y luego otro fuerte salto entre 1896 y 1898 de unas 694.000 hectáreas. Las cifras de Sotilla fueron publicadas primero en 1911, y una de sus principales fuentes fueron los trabajos de la Junta Consultiva Agronómica (JCA). Sin embargo, los datos de la JCA, que son a nivel provincial, pero no nacional como los de Sotilla, tienen cambios mucho más suaves. La cifra de la JCA muestra un aumento solamente de 3,4 a 3,5 millones de hectáreas en 1891-92, y aquí la diferencia se puede explicar por un error en el cálculo de Sotilla para $1891^{11}$. La cifra de la superficie cultivada del trigo entre 1896 y 1898 aumentó 465.000 hectáreas (según JCA), pero unas 450 mil de las cuales se hallaban en solamente siete provincias: Jaén $(+120)$, Málaga $(+92)$, Murcia $(+76)$, Huesca $(+58)$, Zamora $(+54)$ y Canarias $(+50)^{12}$. Pero los errores y las dificultades en interpretar las estadísticas no solamente están relacionados con la superficie cultivada, sino también con los rendimientos. Después de un estudio detallado de la producción triguera entre 1890-94, Arrazola comentó:

«De lo expuesto con tan fatigosa prolijidad, se deduce una desconsoladora enseñanza, y es que tiene en España datos, no ya seguros, ni siquiera aproximados del rendimiento de las cosechas del trigo. Todo lo que se aduce, afirma el convencimiento de que la producción es muy superior a las cifras oficiales que han podido reunirse, y que a falta de otras mejores, han debido exponerse» ${ }^{13}$.

${ }^{10}$ Sotilla (1911 y 1981).

"JCA AMA, leg. 259 (1891) y leg. 260 (1892). Para 1891, Sotilla, en contraste con su método en otros años, obtuvo su cifra de la superficie sembrada con el trigo dividiendo la producción nacional por el rendimiento de trigo medio del país, cuando lo correcto es dividir la producción de cada provincia por el rendimiento medio de la provincia y sumar los totales.

12 Boletin Semanal de Estadística y Mercados (BSEM), 323, 1897, y 418, 1899.

13 Arrazola (1896), p. 34; citado en Sanz (1981), p. 325. 
Sin duda, la calidad de la estadística mejoró bastante durante los últimos diez años del siglo $x I x$, y para el nuevo siglo tenemos información sobre un grupo más amplio de productos ${ }^{14}$. Pero este perfeccionamiento en las fuentes también trae sus propios problemas, porque a veces es difícil determinar hasta qué punto la recuperación de la producción es consecuencia de la política proteccionista a finales del siglo, y en qué medida hay una reducción de la ocultación y una mejora de la estadística ${ }^{15}$.

\subsection{La ganadería}

Las cifras de la ganadería traen más complicaciones todavía, porque el censo de 1891 da resultados más bajos que el de 1865 y que el Catastro de la Ensenada (cuadro 3). Si excluimos el censo de 1891, porque «hay razones para creer que muchas de esas cifras proceden de estimaciones con un origen temporal impreciso y casi siempre, desfiguradas por la ocultación» ${ }^{16}$, y comparamos los dos de 1865 y 1917 - censos de mayor calidad-, observamos que sigue una caída en términos absolutos en cada categoría, excepto el vacuno. En términos de peso total de la cabaña por habitante (o hectárea cultivada), las cifras de 1865 no son superadas antes de la Guerra Civil. Además, a mediados del siglo xvirI, la estimación del tamaño de la cabaña nacional fue casi la misma en términos absolutos que la de 1865 ó 1929, y por eso mucho mayor en número por habitante y hectárea cultivada. Quizá las razones más importantes para explicar esta caída, a largo plazo, fueron los efectos de la desamortización, y una política de autosuficiencia a nivel nacional en la producción de cereales que redujo los pastos disponibles, aumentando los costes de producción, y los pequeños cambios en la renta per capita, que no fueron suficientes para compensar con un aumento en la demanda de la carne y productos lácteos.

En conclusión, no podemos fiarnos totalmente de las fuentes históricas para estimar los cambios en la producción agraria nacional durante el siglo XIX. Por supuesto, esto no significa que las cifras anteriores no tengan

${ }^{14}$ El Grupo de Estudios de Historia Rural (GEHR) ha escrito que «las principales estadísticas oficiales mejoran considerablemente a partir de 1898». GEHR (1983), Apéndice 4.

is Arrazola (1896), p. 10, hablando del JCA, escribió: «Cabe creer que las noticias tan cuidadosamente recogidas por los Ingenieros agrónomos no son todo lo precisas que fueran de desear, y que este trabajo, iniciado hace pocos años, está en vías de perfeccionamiento. Sentado esto, las cifras diminutas de la producción de los años de 1890 a 1892 , y aun de los siguientes, se explican por las dificultades de establecer un servicio de investigación, que tan penosamente se ha planteado en otros países en que los agricultores no tienen tanto recelo en facilitar noticias del rendimiento de sus cosechas." Citado en Sanz (1981), p. 324. Véase, también, Maluquer de Motes (1987), p. 74.

16 Zapata (1986), tomo 1, p. 624. 


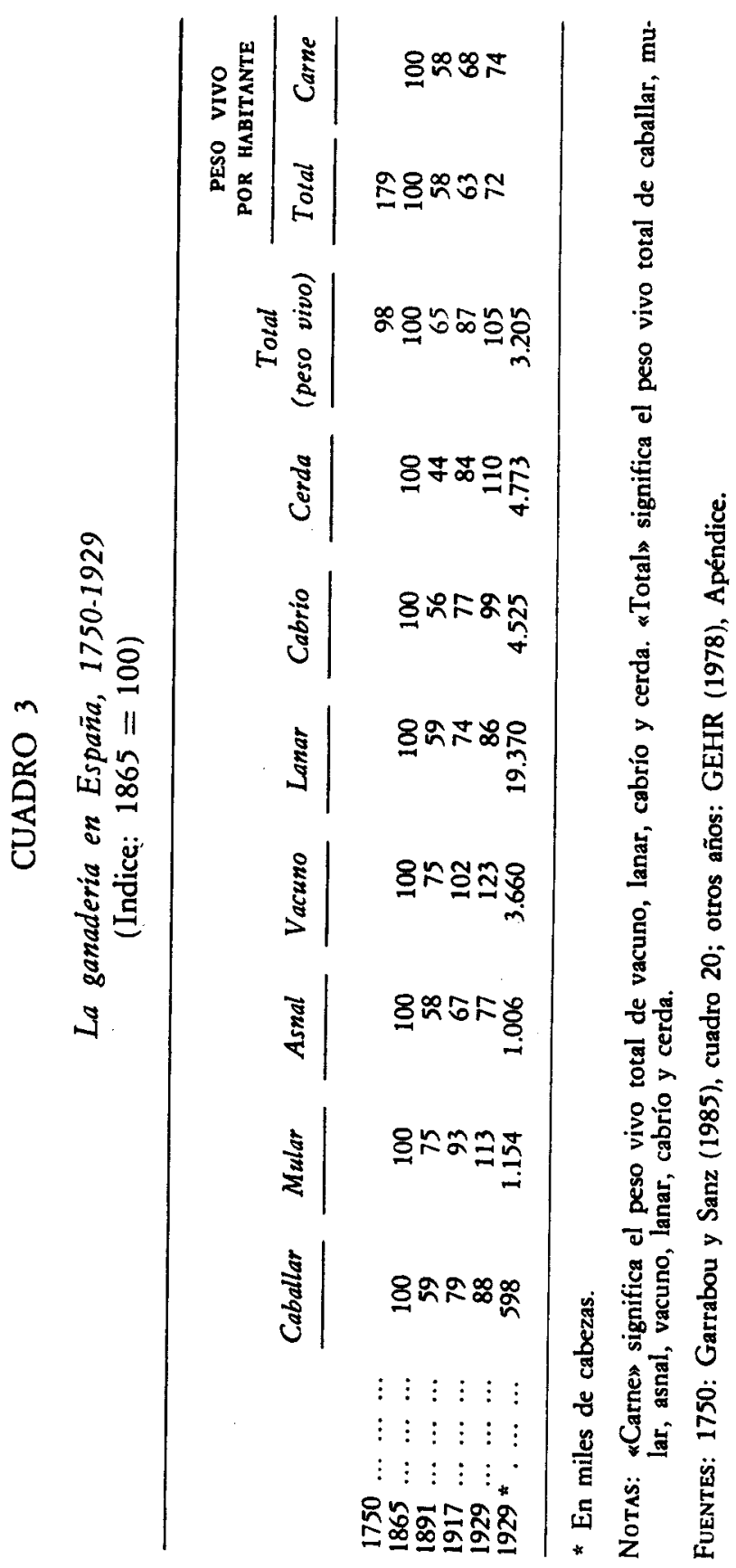


valor para el historiador, sino solamente que es necesario recordar sus limitaciones, especialmente cuando unas series de producción sean comparadas con otras para determinar los ritmos de cambios.

\section{EL CONSUMO DE PRODUCTOS AGRARIOS $Y$ LAS CRISIS DE SUBSISTENCIA}

Para determinar la producción de una cosecha es necesario saber la superficie cultivada $y$ los rendimientos por hectárea. Aunque lo último podría ser estimado con una cierta exactitud, no puede decirse lo mismo de la superficie, por la ausencia de un catastro. Pero hay una manera alternativa de calcular la producción mediante la estimación del consumo de productos agrarios. En el siglo xvin hubo varios intentos, y en el cuadro 4 se reproduce el ejemplo del sumario del Censo de Frutos de Polo y Catalina.

\section{CUADRO 4}

Estimación del consumo por babitante de cereales en el año 1799 (Fanegas *)

\begin{tabular}{|c|c|}
\hline $\begin{array}{lllllllllllll}\text { Cosecha } & \ldots & \ldots & \ldots & \ldots & \ldots & \ldots & \ldots & \ldots & \ldots & \ldots & \ldots\end{array}$ & 48.973 .096 \\
\hline 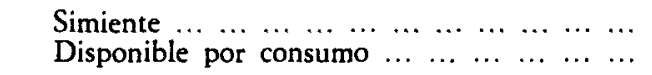 & $\begin{array}{r}7.983 .184 \\
40.989 .912\end{array}$ \\
\hline 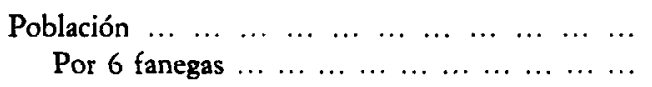 & $\begin{array}{l}10.504 .985 \\
63.029 .910\end{array}$ \\
\hline 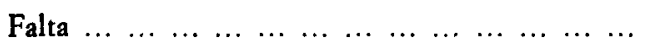 & 22.039 .998 \\
\hline
\end{tabular}

* 6 fanegas es equivalente a 256 kilos.

Fuente: Polo y Catalina (1803), Plan comparativo de los principales objetos que componen la estadistica de las provincias de España.

Los cálculos de Polo y Catalina incluyen el trigo, centeno, «escanda, tranquillón, comuña y otros», maíz y panizo, pero no la cebada, avena, arroz y mijo. La cantidad que ofrece para la semilla ( 16,3 por 100) coincide con otras estimaciones de la época. Las cifras suscitaron las críticas de Fontana, que sostenía que una importación de 22 millones de fanegas «hubiera hecho desaparecer el cultivo del trigo en España» ${ }^{17}$. Pero este déficit

\footnotetext{
${ }^{17}$ Fontana Lázaro (1978), nota 38.
} 
solamente existe si se admite que la cosecha y el consumo por habitante supuestos en el cálculo son verosímiles. Surgen dudas sobre la cosecha que son discutidas más arriba. La cifra de 6 fanegas/habitante al año parece alta, aunque aparece repetidas en el trabajo de Calomarde, Miguel de Zabala (Memoria de 1738) y otros. Moreau de Jonnes, que usó una cifra de 5,9 fanegas, apuntó:

«la costumbre estendida en España y Portugal de hacer puches de harina, y el aumento de consumo de pan, por causa de la falta de carne, debe hacer que esta estimación sea un mínimo, siempre que la prosperidad pública permite a la población el satisfacer enteramente a sus necesidades» ${ }^{18}$.

Suponiendo que el trigo tuviera la misma importancia relativa en el consumo que en su cultivo ( 68 por 100 de los cereales panificables), el Censo de Frutos da una cifra de $180 \mathrm{kilos} /$ habitante al año (neto de simiente). En 1868 el Gobierno hizo una estimación del consumo, para un año de cosecha normal, que arrojó una cifra de 171,5 kilos de trigo por habitante, o 141,7 kilos netos de simiente ${ }^{19}$. Por últimos, podemos comparar estas cifras con las correspondientes a finales del siglo xix. Arrazola estimó un consumo medio (neto de la semilla) de trigo por habitante en España durante el quinquenio $1890-94$ de 123,2 kilos. Este cálculo es diferente que los de 1799 y 1868 , porque las cifras de la producción de trigo han sido (utilizadas y) corregidas por movimientos comerciales con el extranjero. Como hemos visto, Arrazola criticó las cifras de producción por considerarlas demasiado bajas, y el mismo cálculo, hecho para los años 1891-1909, condujo a una cifra de 146 kilos netos por habitante 20 .

Dejando aparte los cereales, las fuentes dicen poco sobre el consumo de otros productos. Siendo el trigo la cosecha más importante en España durante el siglo XIX, existieron grandes diferencias en la dieta entre regiones tan diversas como Galicia y Andalucía, o Castilla y Valencia. La dieta también experimentó cambios significativos, como el uso de la patata en muchos pueblos por primera vez, y por los efectos de los ferrocarriles, que redujeron el coste de transporte de los productos entre regiones. No es posible explicar aquí los cambios en cada producto por razones de espacio y falta de información, pero es imprescindible hacerse una idea más profunda del consumo español durante el siglo xIx.

18 Moreau de Jonnes (1835), pp. 132-133.

19 La Crisis Agricola y Pecuaria (1887), vol. 1b, pp. 144-145.

${ }^{20}$ Arrazola (1896), pp. 9-10. Véase Tortella (1985) para otras observaciones sobre cl consumo de cereales durante el siglo xix. 
En muchos casos la alimentación de subsistencia no era fija, sino que variaría de una época del año a otra, y de cosecha a cosecha, dependiendo esencialmente de lo que era asequible y de los recursos individuales. Así leemos que en Aragón el maíz era un alimento para animales, excepto en los años de escasez de granos para la alimentación, cuando se usaba para hacer pan ${ }^{21}$. Las dificultades de comunicación no facilitaron el movimiento de excedentes, y por eso tampoco se estimuló la producción para el mercado ni la especialización. En 1806, la falta de un mercado hizo que el trigo excedente después de una buena cosecha fuera dado a los cerdos en las calles de Palencia. Una sucesión de buenas cosechas, bajos precios y alta demanda para segar y trillar, actuaría como incentivo para reducir la superficie cultivada, empeorando la situación cuando ocurriese una mala cosecha ${ }^{22}$. A finales del siglo XIX, en la provincia de Soria, las hortalizas que sobraron en muchos pueblos también se emplearon como alimentación para los cerdos por falta de mercado ${ }^{23}$. En el otro extremo, durante los años del hambre de 1812, Madrid vivió prácticamente sin suministros del exterior, y productos como las castañas, las bellotas y la harina de almortas tuvieron una gran demanda. Era ilegal vender en lugares públicos otro tipo de pan que no fuera «el bajo o de munición», un pan que consistía en una «mínima proporción de trigo de ínfima calidad" mezclado con maíz, centeno, cebada y almortas ${ }^{24}$. Pero en el norte de España, especialmente en Asturias, las castañas no fueron simplemente un producto para el consumo durante años de crisis de subsistencia, sino que formaron una parte esencial de la dieta normal ${ }^{25}$. Por último, dado que menos del 20 por 100 de la superficie del país estaba sembrada en 1800 , podemos suponer que la posibilidad de completar la dieta con la caza o plantas silvestres era alta, especialmente durante años de escasez ${ }^{26}$.

Además de la cantidad de alimentos consumidos y de su diversidad, estaba también el tema de la calidad. Fernández García, al escribir sobre la alimentación en Madrid en la época isabelina, apuntó que lo que verdaderamente separaba a las clases bajas de las altas era la calidad de los alimentos ${ }^{27}$. Las quejas por la adulteración de los alimentos eran frecuentes, especialmente durante los años de escasez, cuando los sustitutos del trigo eran de todo tipo,

\footnotetext{
21 Calomarde (1800), p. 69.

"López y Peñalver (1812), pp. 3 y 8.

${ }^{23}$ Dirección General de Agricultura, Industria y Comercio (1891), 3, 165.

${ }^{24}$ Espadas Burgos (1968), p. 612.

${ }_{25}$ Anes (1988), p. 72; para Francia, véase Bruneton-Governatori (1984).

${ }^{26}$ En 1900 , la superficie sembrada representaba el 26 por 100 dé la superficie total (GEHR, 1983, p. 243). Suponiendo que esta superficie había crecido durante el siglo XIX aproximadamente al mismo ritmo que la población, tenemos una cifra del 15 por 100 del país no sembrado en 1800 .

${ }^{2 i}$ Fernández García (1971), p. 132.
} 
y productos potencialmente peligrosos se mezclaban en el pan ${ }^{28}$. La adulteración no estaba limitada al pan, sino que también acontecía con otros alimentos como el aceite de oliva y el vino ${ }^{29}$.

Para determinar la cantidad y los tipos de productos consumidos hay que calcular un «balance de alimentos». El método es simple: a la suma de la producción nacional de cada producto se le sustraen las necesidades de semilla, la parte usada como pienso y los desperdicios. En este total se ha considerado el balance del comercio exterior: las importaciones menos las exportaciones. El total así obtenido se ha dividido por el número de habitantes. Dadas las dificultades que surgen con las fuentes para los primeros años de la década 1890, y la falta de información sobre muchos productos, el año base aquí elegido es 1900. Para superar los problemas asociados con las fluctuaciones de la cosecha, se ha utilizado la media de las cosechas de 1897-1901 (véase Apéndice 1). Para posibilitar la comparación de diferentes productos, los alimentos se han convertido a unidades de calorías (cuadro 5). Con la infor-

\section{CUADRO 5}

Consumo de alimentos por babitante $y$ año

\begin{tabular}{|c|c|c|c|c|c|}
\hline & \multicolumn{3}{|c|}{$1900 *$} & \multicolumn{2}{|c|}{$1930 * *$} \\
\hline & $\begin{array}{c}\text { Calorias } \\
\quad \text { kilo }\end{array}$ & $\begin{array}{l}\text { Cantidad } \\
\text { kilos/bab. }\end{array}$ & Calorias & $\begin{array}{c}\text { Cantidad } \\
\text { kilos/bab. }\end{array}$ & Calorias \\
\hline \multicolumn{6}{|l|}{ Cereales } \\
\hline 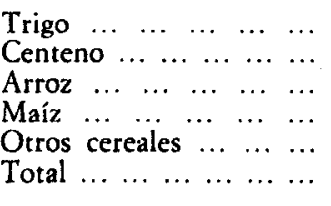 & $\begin{array}{l}3.420 \\
2.800 \\
3.420 \\
3.180 \\
2.800\end{array}$ & $\begin{array}{r}106,56 \\
18,61 \\
6,68 \\
10,31 \\
2,23\end{array}$ & $\begin{array}{r}364.435 \\
52.108 \\
22.846 \\
32.786 \\
6.244 \\
478.419\end{array}$ & $\begin{array}{r}111,24 \\
14,84 \\
8,93 \\
7,80\end{array}$ & $\begin{array}{r}380.441 \\
41.552 \\
30.541 \\
24.804 \\
\\
477.337\end{array}$ \\
\hline \multicolumn{6}{|l|}{ Leguminosas } \\
\hline 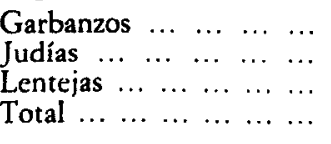 & $\begin{array}{l}2.920 \\
2.790 \\
2.960\end{array}$ & $\begin{array}{l}3,82 \\
5,29 \\
0,58\end{array}$ & $\begin{array}{r}11.154 \\
14.759 \\
1.717 \\
27.630\end{array}$ & $\begin{array}{l}4,46 \\
5,46 \\
0,52\end{array}$ & $\begin{array}{r}13.023 \\
15.233 \\
1.539 \\
29.796\end{array}$ \\
\hline 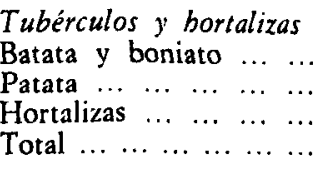 & $\begin{array}{l}970 \\
700 \\
233\end{array}$ & $\begin{array}{r}0,00 \\
104,98 \\
84,75\end{array}$ & $\begin{array}{l}73.486 \\
19.747 \\
93.233\end{array}$ & $\begin{array}{r}1,98 \\
167,65 \\
135,34\end{array}$ & $\begin{array}{r}1.921 \\
117.355 \\
31.534 \\
150.810\end{array}$ \\
\hline
\end{tabular}


CUADRO 5 (Continuación)

Consumo de alimentos por babitante $y$ año

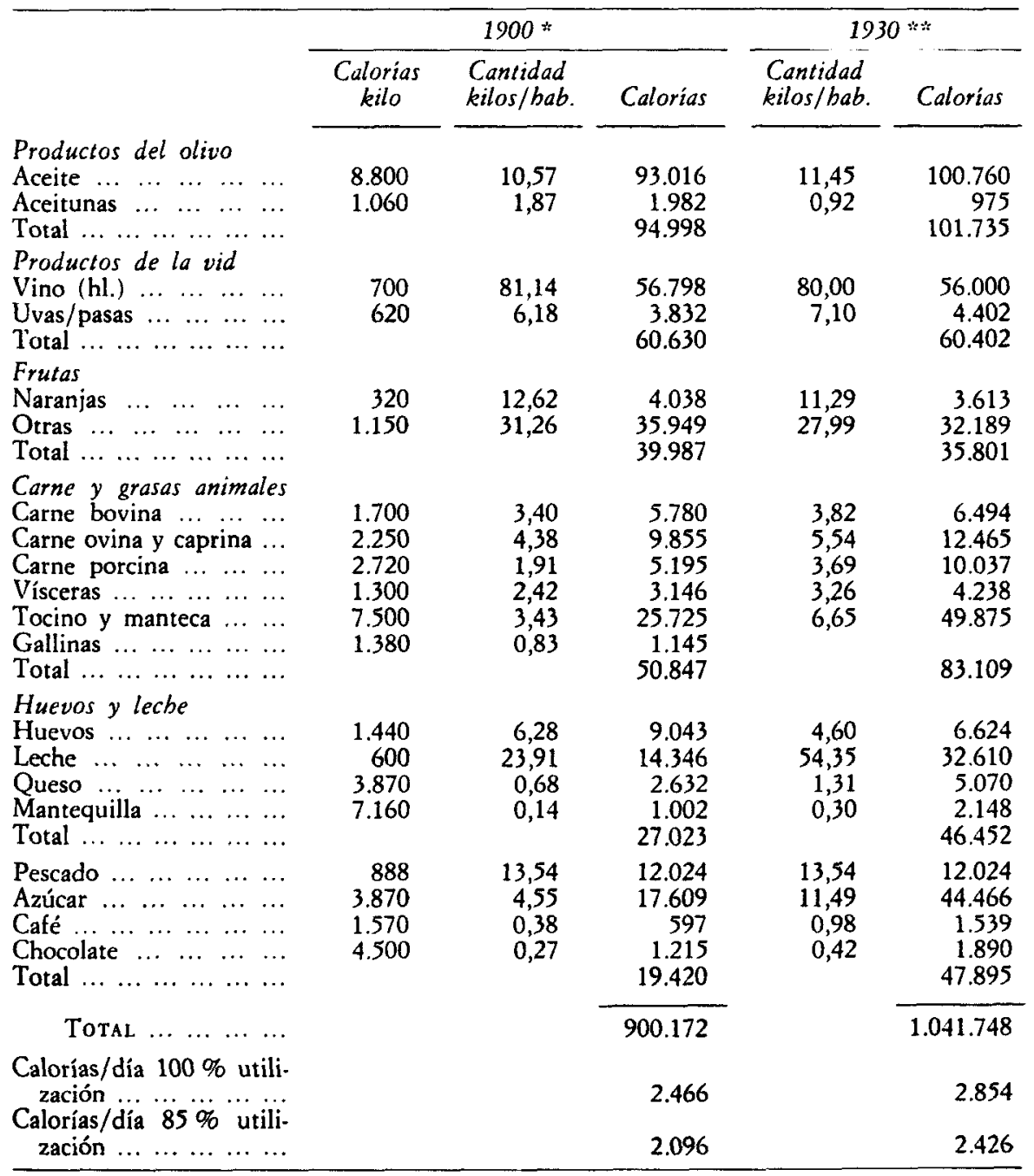

* El año 1900 corresponde a los años 1897.1901.

* El año 1930, a los años 1929-33.

Nota: Hemos supuesto que la patata tuvo la misma importancia en la categoría «patatas y hortalizas" en 1900 como en 1929-33, y la naranja, la misma importancia en la categoría "frutas" entre las dos fechas.

Fuentes: Apéndice 1 y Barbancho (1960), pp. 271-312. 1897-1901: Comisión Extraparlamentaria del Impuesto de Consumos, tomo 1, cuadro 58, para huevos y gallinas; pescado: la misma cifra ha sido utilizada como 1930. 
mación obtenida de los años 1929-33, ha sido posible calcular, aproximadamente, todos los tipos de productos en 1900, y con ella hemos calculado un

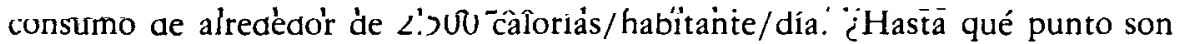
aceptables estas cifras para la España de 1900?

Las cifras de calorías deberían interpretarse como el requisito básico ideal de la dieta energética. Un cálculo, en base a estudios en Estados Unidos, sugirió un consumo de 2.400 calorías para el hombre de referencia y 1.760 para la mujer ${ }^{30}$. Adecuar estas cifras americanas para los españoles del siglo xIx, con su propia estructura de edades, clima y esfuerzo en el trabajo, sería muy difícil. Además, como Srinivasan ha puesto de manifiesto, «hay una amplia variabilidad en la energía consumida entre individuos con niveles de salud similares y entre los mismos sujetos a lo largo de un mismo período" ${ }^{31}$.

Un consumo de 2.500 calorías/día no es muy diferente a la cifra situada entre 2.000 y 2.500 calorías/habitante vigente en Inglaterra a finales del siglo xviII, o la de 2.282 para el Tercer Mundo en la actualidad ${ }^{32}$. Pero es más adecuado utilizar a Francia, Portugal e Italia como punto de referencia, por la mayor similitud del clima y tipos de cosechas y alimentos. Para Francia, Toutain ha obtenido, utilizando métodos similares a los nuestros, un resultado de 3.192 calorías/habitante en 1895-1904. Este país llegó al nivel de 2.500 en 1845-54, y en el decenio siguiente progresó aproximadamente 300 calorías más ${ }^{33}$. Para Portugal no tenemos datos sobre calorías, pero entre 1846 y 1912 el consumo de cereales (excluyendo el arroz) se situó entre 148 y 160 kilos/ habitante ${ }^{34}$. En España la cifra para los mismos productos fue de 182 kilos en 1900. Por último, en Italia las calorías/habitante cayeron desde 2.637 en 1861-80, hasta 2.158 en $1880-1900{ }^{35}$. La aproximación aquí ofrecida del consumo de calorías en España en 1900, obtenida por este método, parece plausible.

El cálculo del cuadro 5 de 2.500 calorías corresponde al consumo potencial del país y no, por supuesto, al consumo real. Hay pérdidas que surgen del transporte, almacenamiento, cocina y la mala conservación de los productos después de la fase del mercado al por menor. Una indicación del orden de magnitud se obtiene comparando otros «balances de alimentos» de un país (calculados como aquí) con estudios de cantidades consumidas en familias

${ }^{30}$ Una persona de referencia: $20-39$ años, saludable, de una actividad media de 8 horas diarias, ligeramente activa por $4-6$ horas, actividad en ocio o en actividades en la casa durante 2 horas y en la cama 8 horas. Lipton (1983), pp. 9-10.

"Srinivasan $(1981)$, p. 3.

32 Shammas (1984), pp. 259-269; Greig (1982), p. 118.

${ }^{33}$ Toutain (1971), p. 1977. En estas cifras no están incluidas las bebidas alcohólicas.

${ }^{34}$ Lains (1987).

${ }^{35}$ Galeotti y Livi (1964); citado en Livi-Bacci (1988), cuadro 15. 
actuales. Por ejemplo en Japón, en 1975, un estudio de 15.000 familias durante cinco días produjo una media de 2.188 calorías/habitante, contra 2.800 según la hoja de ballance: una ditereńcia de un 22 por 100. En China la diterencia fue de un 12 por 100 en 1983, 2.380 calorías en vez de 2.710 obtenidas por el método del balance, aunque Smil prefiere una cifra más cercana al 18 por 100 menos ${ }^{36}$. Si para España se utiliza un cociente consumo/balance de 0,85 , entonces las 2.500 calorías se reducen aproximadamente a 2.100, que es la cifra que se usa en este trabajo.

Se puede notar que en la dieta española de 1900 los cereales, leguminosas y patatas constituyeron el 64 por 100 de las calorías consumidas, cifra que había bajado poco en 1931 (60 por 100). La poca cantidad de carne, café, azúcar, etc., muestra la pobreza de la dieta para la mayoría de la población. Sin embargo, para obtener alimentos de esta naturaleza se utilizaba un alto porcentaje de los presupuestos familiares, según un estudio de Conard ${ }^{37}$ :

\begin{tabular}{|c|c|c|}
\hline & $A \tilde{n} o s$ & $\begin{array}{l}\text { Porcentaje } \\
\text { de la renta } \\
\text { gastada en } \\
\text { alimentación }\end{array}$ \\
\hline $\begin{array}{llllllllllllll}\text { Minas de } & \text { Bilbao } & \ldots & \ldots & \ldots & \ldots & \ldots & \ldots & \ldots & \ldots & \ldots & \ldots & \ldots & \ldots \\
\text { Minas de } & \text { Asturias } & \ldots & \ldots & \ldots & \ldots & \ldots & \ldots & \ldots & \ldots & \ldots & \ldots & \ldots & \ldots \\
\text { Madrid } \ldots & \ldots & \ldots & \ldots & \ldots & \ldots & \ldots & \ldots & \ldots & \ldots & \ldots & \ldots & \ldots \\
\text { Barcelona } & \ldots & \ldots & \ldots & \ldots & \ldots & \ldots & \ldots & \ldots & \ldots & \ldots & \ldots & \ldots \\
\text { Barcelona } & \ldots & \ldots & \ldots & \ldots & \ldots & \ldots & \ldots & \ldots & \ldots & \ldots & \ldots & \ldots \\
\text { Barcellon } & \ldots & \ldots & \ldots & \ldots & \ldots & \ldots & \ldots & \ldots & \ldots & \ldots\end{array}$ & $\begin{array}{l}1904 \\
1913 \\
1905 \\
1914 \\
1919\end{array}$ & $\begin{array}{l}72,7 \\
68 \\
75 \\
65,7 \\
74,2\end{array}$ \\
\hline
\end{tabular}

Es probable que estas categorías de trabajadores gastaran más alimentos que la media, pero también lo es que sus ingresos fueran más altos que en el campo. En un estudio del Instituto Nacional de Estadística de 1958, que excluye «las clases sociales altas», el gasto en alimentación representa el 55 por 100 del total de gastos ${ }^{38}$. Entonces los españoles no solamente gastaron un alto porcentaje de sus salarios en comida, sino que una alta proporción de su dieta consistió en productos básicos.

La dieta española era pobre en 1900 , con un consumo de 2.100 calorías/ día, pero es difícil determinar desde la historiografía si aquélla representaba una mejora o un empeoramiento de la situación en los años anteriores. Por un

\footnotetext{
${ }^{36}$ Smil (1986), pp. 32-40.

${ }^{37}$ Conard (1974), p. 304.

${ }^{36}$ Barbancho (1961), p. 54.
} 
lado, varios historiadores han comentado que la tierra sufrió rendimientos decrecientes durante la segunda mitad del siglo xIx, por lo que los años de carestía fueron más frecuentes. Por otro lado, ha surgido una visión mucho más optimista que propugna un crecimiento de la renta per capita, y un fuerte aumento en las exportaciones de productos agrarios. A continuación examinaremos esto.

En los años posteriores a las guerras napoleónicas, la producción agraria aumentó lo suficiente para alimentar una población creciente sin necesidad de importar cereales; incluso produjo un ligero excedente para exportar. Sin em. bargo, Sánchez-Albornoz ha escrito:

«En el largo plazo, tales éxitos quedaron contrarrestados por los inconvenientes surgidos al aplicarse esta política. La producción cerealera aumentó notablemente, pero por extensión del área sembrada y no merced a un incremento en los rendimientos. Tierras de capacidad productiva decreciente fueron puestas en cultivo, sin recurrir a una tecnología más avanzada. El empleo de más brazos en estas actividades se tradujo en un incremento de la población rural. La productividad por unidad de superficie o por hombre disminuyó, tornando el nivel de vida del común de los españoles más precario y por ende más vulnerable a las calamidades naturales» ${ }^{39}$.

Una población más expuesta a «las calamidades naturales» a causa de la expansión de la agricultura es también una característica de la agricultura española de esta época, según Nadal:

«la segunda mitad del siglo xIx conoce de nuevo el viejo desequilibrio entre hombres y recursos. La reiteración de las crisis de subsistencias —en 1857, 1868,1879, 1887 y 1898- aportan, a mi juicio, la prueba más clara de la incapacidad de la nación para subvenir a sus necesidades más perentorias» ${ }^{40}$.

La relación entre la pobreza, el tamaño de la cosecha y el hambre es compleja, y su forma suele cambiar según el nivel de desarrollo en un país. Amartya Sen ha mostrado que la causa principal de varias hambres en años recientes en países del Tercer Mundo no fue la caída en la oferta de alimentos del pais, sino cambios significativos de la capacidad de ciertos sectores de la

${ }^{39}$ Sánchez-Albornoz (1977), p. 43.

4 Nadal (1975), p. 22. 
población y, en ciertas regiones, para obtener por medio del mecanismo del

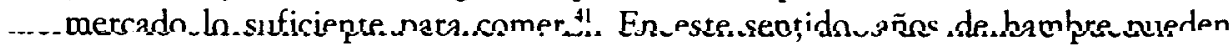
ocurrir no solamente por la reducida oferta de alimentos (la cosecha y las dificultades, legal y física, de transportar excedentes a regiones de escasez), sino también por la ausencia de una demanda efectiva de la población en cuestión. Durante el Antiguo Régimen, el gobierno y las ciudades, en un intento de superar los defectos del mercado, regularon el comercio de granos y construyeron pósitos. En el siglo xix ocurrieron dos cambios de importancia. Primero, con la libertad de comercio interior, la mejora en los sistemas de transporte, especialmente en los ferrocarriles, aumentó la capacidad de un país de transportar grandes cantidades de cereales de un sitio a otro con más rapidez. Con la mayor integración del mercado, la diferencia en los precios de trigo entre las regiones disminuyó durante el siglo ${ }^{42}$. Dado un mecanismo adecuado que permita el transporte de cantidades suficientes de trigo para reducir los altos precios en comarcas donde se hubiera malogrado la cosecha, las hambres solamente pueden ocurrir a causa de una falta de im. portaciones, o por falta de una demanda efectiva de un sector de la po. blación.

El segundo cambio de importancia fue la política de importación de cereales, dado que las cosechas de trigo en las tierras de secano de España sufrieron altas y bajas sin consideración de la presión de la población sobre los recursos. Hemos visto que entre 1919-35 la media de la cosecha de trigo fue 3.997 mil toneladas, con una desviación estándar de 503,2. La mayor cosecha fue de 5,1 millones de toneladas en 1934, y la menor de 3,3 millones en 1924 y 1928. Entonces la cuestión que se plantea no es tanto la capacidad de la agricultura nacional para producir suficiente cada año, sino la eficacia del sistema para abastecer los años de déficit, o para vender los excedentes en años de buenas cosechas. Sánchez-Albornoz ha indicado la importancia del comercio exterior y del gobierno en el suministro de provisiones en las crisis de 1857 y 1868, y cómo los errores políticos del momento agravaron los problemas ${ }^{43}$. En la época de estas dos crisis de subsistencias, España era todavía un país exportador de trigo, y los agricultores se opusieron a las importaciones, incluso en años de altos precios ${ }^{44}$. El año 1868 no fue el último de hambre en España, pero a partir de 1882, el balance comercial

"Sen (1981). Las hambres tratadas son las de Bengala, 1943; Etiopía, 1972; Sahel, 1973-74, y Bangladesh, 1974. Véanse, también, los trabajos de Tilly (1983) y Mokyr (1988) para una visión más amplia de la contribución de la obra de Sen para el historiador.

42 Sánchez-Albornoz (1975); Garrabou y Sanz (1985), pp. 13-67.

43 Sánchez-Albornoz (1977), para 1857, pp. 30-32, 46-52; 1868, p. 85. También, Garrabou (1980).

"Las estadísticas anuales del comercio exterior, que empezaron en 1849 , no muestran ninguna importación del trigo o harina entre 1849-55 y 1860-66. 
del país fue siempre negativo en los cereales y la harina. Además, la mayor integración del mercado mundial, junto con la caída en precios a partir del año 1873, facilitaron el trabajo del Gobierno de superar los efectos de un fracaso de la cosecha interior. Sin embargo, las hambres locales solamente podrían desaparecer cuando la población más expuesta al riesgo tuviese fondos suficientes para comprar en el mercado productos para satisfacer sus necesidades. A este respecto, el problema siguió en Andalucía después de la construcción de los ferrocarriles, dada la falta de trabajo en algunos años y los escasos recursos de la población para atraer abastecimientos de otras regiones de España o el extranjero ${ }^{45}$.

A largo plazo, también ocurrió una "compresión del consumo campesino" en algunas partes del país ${ }^{46}$. El crecimiento de la población y la mayor roturación seguramente iban acompañados por rendimientos decrecientes, por ejemplo, en partes de Castilla, especialmente donde predominaba el pequeño cultivo (minifundio). Un factor de importancia para los rendimientos en esta región fue el comportamiento del lanar. El aumento en los costes de producción, y la caída en la demanda de lana española en el mercado internacional a partir de la década de 1820 , afectaron negativamente a los rebaños trashumantes ${ }^{47}$. Para la producción cerealícola, la decadencia de la trashumancia y la Mesta, en teoría, presentaba dos factores favorables: la posibilidad de roturar los mejores pastos antes reservados para la trashumancia, y la sustitución de la oveja trashumante por la estante, con su mayor aprovechamiento del estiércol para la agricultura. A largo plazo, la competencia de la industria algodonera, utilizando materias primas importadas, redujo los beneficios de la ganadería lanar estante, y su número de cabezas cayó durante una época de expansión de la superficie cultivada ${ }^{48}$. Las pocas oportunidades de diversificación de la producción en Castilla la Vieja resultó en la emigración como la solución cada vez más frecuente a las dificultades económicas durante la segunda mitad del siglo XIX.

En otras partes del país, especialmente en el Mediterráneo, la variedad de la producción fue mayor, y el mercado exterior ofreció la posibilidad de cultivar la tierra de forma más intensiva que con la rotación cereal y de aumentar la productividad. Durante el último tercio del siglo xIx, España participó más en el comercio exterior, con un fuerte aumento en las exportaciones $(\mathrm{e}$ im-

${ }^{45}$ En el último cuarto del siglo, la tendencia de los precios de alimentos fue de estancamiento, mientras que la renta per capita subió. Sin embargo, la mala distribución de la renta y la falta de trabajo en Andalucía significaron que las hambres siguieron hasta el siglo xx. Para la oferta de trabajo en la agricultura en Ándalucía, véase Simpson (1988).

*6 Sánchez-Albornoz (1977), p. 19.

47 García Sanz (1978) y Llopis Agelán (1982).

4 En Castilla la Vieja-León, el número de lanares cayó de unos 6,9 millones en 1865 hasta 4,3 millones en 1917. GEHR (1978), Apéndice cuadro 3. 
portaciones) y una caída relativa en la importancia del trigo en la agricultura española (véase el cuadro 6). En la década 1870-79, la cantidad de trigo y

\section{CUADRO 6. A}

La contribución de la agricultura española al comercio exterior. Estimación de la superficie cultivada dedicada al comercio exterior (Miles de hectáreas)

\begin{tabular}{|c|c|c|c|c|c|}
\hline & Trigo & Vino & Aceite & Naranjas & Total \\
\hline $\begin{array}{lllll}1850-59 & \ldots & \ldots & \ldots & \ldots \\
1860-69 & \ldots & \ldots & \ldots & \ldots \\
1870-79 & \ldots & \ldots & \ldots & \ldots \\
1880-89 & \ldots & \ldots & \ldots & \ldots \\
1890-99 & \ldots & \ldots & \ldots & \ldots \\
1900-09 & \ldots & \ldots & \ldots & \ldots \\
1850-1909 & \ldots & \ldots & \ldots\end{array}$ & $\begin{array}{r}39 \\
7 \\
84 \\
-188 \\
-263 \\
-318 \\
-107\end{array}$ & $\begin{array}{r}89 \\
115 \\
196 \\
527 \\
476 \\
205 \\
268\end{array}$ & $\begin{array}{r}69 \\
109 \\
118 \\
141 \\
142 \\
252 \\
139\end{array}$ & $\begin{array}{r}2 \\
5 \\
6 \\
12 \\
26 \\
10\end{array}$ & $\begin{array}{l}197 \\
230 \\
402 \\
486 \\
367 \\
165 \\
308\end{array}$ \\
\hline
\end{tabular}

Fuentes: Comercio exterior: Estadistica(s) del comercio exterior. Producción: Trigo: rendimiento $1849-1890,7,9$ QM, la media de $1891-1905$ (Sotilla). Vino: vino 1850 . 1897, $16 \mathrm{hl} / \mathrm{ha}$. (coeficientes de conversión). Uvas: $23 \mathrm{QM} / \mathrm{ha}$. (Sotilla, 1891. 1910), y pasas, 0,321 (Ministerio de Agricultura, 1932, pp. 130-131). Aceite: aceitunas, 8,06 QM/ha.; aceite, 19 kilos/100 kilos aceitunas. Naranjas: 18611909, 15 toneladas/ha. (Sanz Bremón, 1979, pp. 270-274).

CUADRO 6. B

Saldo de la balanza de mercancias agrarias

\begin{tabular}{|c|c|c|c|c|c|c|c|}
\hline & \multicolumn{3}{|c|}{ MILLONES PESETAS-ORO } & \multicolumn{3}{|c|}{ MILLONES PTAS. CORRIENTES } & \multirow{2}{*}{$\begin{array}{l}\text { Trigo } \\
\text { equiv. * }\end{array}$} \\
\hline & Exp. & Imp. & Saldo & $\operatorname{Exp}$. & $\operatorname{Imp}$ & Saldo & \\
\hline $\begin{array}{lll}1855.59 & \ldots & \ldots \\
1875-79 & \ldots & \ldots \\
1890-94 & \ldots & \ldots \\
1910-13 & \ldots & \ldots\end{array}$ & $\begin{array}{l}145 \\
197 \\
405 \\
571\end{array}$ & $\begin{array}{l}125 \\
129 \\
179 \\
256\end{array}$ & $\begin{array}{r}20 \\
68 \\
226 \\
314\end{array}$ & $\begin{array}{l}141 \\
198 \\
460 \\
618\end{array}$ & $\begin{array}{l}122 \\
129 \\
202 \\
278\end{array}$ & $\begin{array}{r}19 \\
69 \\
258 \\
341\end{array}$ & $\begin{array}{r}808 \\
3.067 \\
12.693 \\
15.602\end{array}$ \\
\hline
\end{tabular}

Nota: * Miles de hectolitros. El saldo (pesetas corrientes) lo divido por el precio medio de trigo en España, más las importaciones de trigo y harina, menos las exportaciones.

Fuentes: Comercio exterior: Prados (1984), cuadro 4, y (1986), cuadro Ap. 3. Precios de trigo: 1855-59, Garrabou y Sanz (1985), Barcelona y Valladolid; GEHR (1980), cuadro 14. 
harina exportada fue el equivalente de la producción de 84.000 hectáreas; en 1900-09, el país importó el equivalente de la cosecha de 318.000 hectáreas de trigo en España. La alta demanda de vino español estimuló la producción en muchas provincias y cada año se dedicaba a la exportación aproximadamente medio millón de hectáreas entre 1880-1900. No obstante, esta cifra tiene que ser modificada bastante si se tienen en cuenta las grandes importaciones de alcohol y algodón. El alto precio disminuyó el consumo de vinos en el mercado interior que permitió un gran negocio en bebidas baratas producidas utilizando alcohol extranjero. Según un cálculo de 1885 , fecha de precios máximos del vino, un 24 por 100 del vino consumido en España, el equivalente de unas 300.000 hectáreas, fue «fabricado», una gran parte con alcohol importado ${ }^{49}$. Entonces la superficie neta dedicada al comercio exterior probablemente no cambió mucho durante la segunda mitad del siglo xIX. Sin embargo, en términos de valor, el balance del comercio de alimentos aumentó a un ritmo anual de 5,1 por 100 entre $1855-59$ y $1910-13$ (cuadro 6). Si el saldo es medido en términos de la capacidad de importar trigo (equivalentes trigo), el ritmo de crecimiento del saldo es casi el mismo, de un 5,2 por 100 , medida en precios nacionales. Sin la protección arancelaria, que permitió una caída de solamente 8 por 100 entre 1855.59 y 1910.13 en el precio del trigo en España, la capacidad de importar trigo hubiera sido mucho mayor; entre las mismas fechas el precio del trigo en Inglaterra cayó un 44 por $100^{50}$.

No obstante, el dinamismo del comercio exterior afectó a una pequeña parte de la producción española. El cuadro 6 muestra que después de la reducción de la demanda de los vinos españoles en Francia, solamente medio millón de hectáreas estaba dedicado al comercio exterior en la década 1900-09, lo que representaba un 2,6 por 100 de la superficie cultivada ${ }^{5}$. En términos de valor, las exportaciones españolas en 1900 representan entre el 3,5 y 12 por 100 del producto agrario, según se haga el cálculo ${ }^{52}$.

\footnotetext{
49 Antúnez (1887), p. 16. El precio del vino en San Pere de Ribes fue el más alto en 1885 , entre 1856 y 1915 (precios corrientes).

${ }_{50}$ Mitchell y Deane (1971), p. 88.

${ }^{51}$ La superficie cultivada en España en 1910 fue de 18,9 millones de hectáreas, que incluyen 6,2 millones de tarbecho blanco y erial r.o permanente. GLHR (1983), Apéndize 1 .

${ }_{52}$ El valor total del producto agrario en 1900 (1897-1901), según GEHR (1983), Apéndice 2, es 4.386 millones de pesetas. Las cantidades de vino, pasas, uvas, aceite de oliva, aceitunas, naranjas y almendras para los años 1897-1901 vienen de las cifras del comercio exterior, y el precio por unidad, calculado a partir de Sotilla (1981) y JCA (1902); el valor total es de 153 millones, o. 3,5 por 100. Esta cifra es un mínimo porque supone que la calidad de los productos exportados fue la misma que para el consumo doméstico. Una cifra más alta, el 12 por 100 , es obtenida dividiendo el valor de las exportaciones de alimentos (1890-94 y 1910-13) por el total en $1891-95$ y 1910 -cuadro 6 y GEHR (1983), Apéndice 2-. Esta cifra es un máximo porque incluye el valor añadido de las industrias agrarias.
} 


\section{MODELOS INDIRECTOS PARA ESTIMAR LA PRODUCCION AGRARIA}

Ante la dificultad existente para construir un índice de la producción agraria a partir de las fuentes oficiales, es ineludible recurrir a otros métodos para estimar los cambios a largo plazo. Recientemente, Leandro Prados ha presentado los resultados de un método indirecto para estimar la demanda de los productos agrarios en el siglo xix y de esta forma comprobar la exactitud de las fuentes de la época ${ }^{53}$. El método de Prados, que también ha sido utilizado por Crafts y Jackson para la Inglaterra del siglo xvin, merece un examen más profundo ${ }^{54}$. Según este modelo:

$$
\pi D=n \cdot \pi Y+e \cdot \pi R+\pi P
$$

donde $\pi$ corresponde a cambios anuales, $D$ es la demanda de productos agrarios, $P$ es la población, $Y$ es la renta per capita en términos reales, $R$ son los precios relativos de productos agrarios, $n$ la elasticidad renta de la demanda de los productos y $e$ la elasticidad precio de la demanda.

Existen varios problemas con este modelo. Primero, Tortella y O'Brien han apuntado la circularidad del razonamiento que se subyace al método, porque el uso de cifras de la renta nacional supone un conocimiento previo de la producción agraria ${ }^{55}$. Segundo, los cambios en la demanda no significan cambio en la producción real. Por último, no podemos estar seguros de que no hubiera cambios en la distribución de la renta que afectaran a la demanda de los productos.

Los resultados del cálculo obtenido con ese método para 1800-90, sin embargo, no parecen inaceptables. Con una elasticidad renta de 0,7 y una elasticidad precio de $-0,5$, el producto por habitante fue más o menos el mismo en 1890 y en 1800 . Con elasticidades de 1,0 y $-0,3$, el aumento fue pequeño, entre 0,3 y 0,4 por 100 al año. El cambio espectacular, según los cálculos de Prados, ocurrió entre 1890 y 1910, con un aumento de entre 0,4 y 1,3 por 100. Estas cifras significan, con elasticidades de 0,7 y $-0,5$, un incremento en el producto total del período $1800-1900$ de entre 0,6 y 0,8 por 100 al año; y con elasticidades 1,0 y $-0,3$, de un 0,9 y 1,1 por $100^{56}$.

Dado que el modelo tiene sus defectos y que las fuentes utilizadas (la renta nacional, la población, las elasticidades y los precios relativos de los productos agrarios) no tienen un alto nivel de fiabilidad para el siglo XIX,

53 Prados de la Escosura (1988), cap. 3.

54 Crafts (1976), pp. 226-235, y Jackson (1983), pp. 333-351.

ss Tortella Casares (s. f.) y O'Brien (1985), p. 773.

56 Prados de la Escosura (1988), cuadros 3-5. 
estas amplias aproximaciones del crecimiento del sector reducen el riesgo de equivocarse. Por lo tanto, la decisión de Prados de elegir el ritmo de crecimiento más alto resultante de sus cálculos para la agricultura española en el siglo XIX no es muy aceptable. Y aún lo es menos porque su decisión se basa en la similitud de estos resultados con los cálculos de la producción y los precios, sacados de fuentes como el Censo de Frutos o de la Junta General de Estadística de $1857^{57}$. En el resto del artículo veremos si hay datos para apoyar las conclusiones «optimistas» de Prados, o si la realidad se acerca más a la opinión de Tortella, quien ha escrito que «si la agricultura hubiera crecido mucho en el XIX, como los niveles de desarrollo eran muy bajos en 1900, el punto de partida hubiera tenido que ser a principios de siglo cercano a cero" ${ }^{58}$.

La importancia de los cambios en el tamaño de la población sobre la demanda de productos agrarios en España durante el siglo XIX no parece discutible. Entre 1797 y 1900, la población española aumentó desde 10,5 millones hasta 18,6 , un crecimiento anual de un 0,55 por 100 . Los efectos de los cambios en la renta per capita y en los precios agrarios sobre la demanda de alimentos, y en la producción agraria española, son más difíciles de determinar.

En teoría, el aumento de la renta nacional en la España del siglo xix también tendría que afectar al consumo. Según la ley de Engel, el porcentaje de la renta per capita gastado en la alimentación disminuirá con el aumento de la renta, si no hay cambios en los precios relativos ni en los gustos de los consumidores. Con los niveles de renta per capita que tenía España en el siglo xIx y bien entrado el $\mathrm{xx}$, la experiencia de otras economías indica que las preferencias o hábitos de consumo cambian. En el Reino Unido, por ejemplo, parece que entre 1880-89 y 1900-09 la proporción de la renta dedicada al consumo de alimentos permanece prácticamente constante; el incremento en la renta real se usa «no para adquirir más de la misma cosa, sino más bien para incrementar la variedad y aumentar el nivel de alimentación" ${ }^{59}$. Para la clase trabajadora inglesa, en aquel momento, lo más importante era introducir alguna variedad en la alimentación, basada en el cereal y la pa-
tata ${ }^{60}$.

La renta per capita, según los cálculos de Prados, aumentó a un ritmo

${ }^{57}$ Con un índice de 100 en 1800 , las estimaciones de Prados de los cambios en la productividad de la mano de obra entre 1800 y 1910 fluctúan entre un mínimo de 96 y un máximo de 150; el producto por hectárea presenta un mínimo de 127 y un máximo de 198 . Prados (1988), cuadros 3-5. Para una crítica del uso del "Censo de Frutos», véase Fon-
tana Lázaro (1967).

s8 Tortella (1987), p. 57.

59 Supple (1981), p. 133.

60 Oddy (1976). 
anual de entre un 0,2 y un 0,3 por 100 entre 1800 y 1860 , y un 1,0 por 100 entre 1860 y 1890 , aunque si no tenemos unos mejores cálculos de la producción agraria, tampoco podemos confiar demasiado en estas cifras ${ }^{61}$. Sería de interés, sin embargo, conocer la información que existe sọbre los cambios en el consumo de productos que sustituyeron a los cereales, ya que cabe suponer que su importancia en la dieta española aumentó, al mejorar la renta per capita. Por ejemplo, entre 1850-59 y 1890-99, el consumo per capita de café aumentó un 371 por 100; el bacalao, un 40 por 100; el azúcar (entre $1850-59$ y 1900-09), un 124 por 100 , y solamente el cacao tuvo una caída de un 23 por $100^{62}$. Pero el balance de alimentos de 1900 (cuadro 5) muestra que las cantidades de estos productos fueron pequeñas, y los cambios en el consumo probablemente limitados a las clases urbanas. Además, con la excepción del azúcar a finales del siglo XIX, estos cambios no tuvieron ninguna importancia para la agricultura española.

Cabe suponer que fue, quizá, con la demanda de carne por donde los cambios en la renta per capita estimularon la agricultura española. Sin embargo, el sector de la ganadería muestra una caída importante en la oferta de sus productos, si aceptamos los censos de 1865, 1917 y 1929 (véase cuadro 3). En parte es posible explicar esta disminución por un aumento en los costes de producción, dado que la venta de tierras comunales privó a los campesinos de la posibilidad de alimentar su ganado gratis o con costes reducidos. Otra explicación posible es que la mala distribución de la renta redujo el consumo de carne de la mayor parte de la población. La comercialización de productos lácteos, por otra parte, no tuvo importancia hasta el siglo $\mathbf{x x}^{63}$. Observamos, como conclusión, que los efectos de un aumento en la renta, durante esta época, fue de poca importancia en la diversificación de la dieta de productos básicos a productos de lujo y semilujo.

El consumo de productos básicos en la dieta sí que cambió. Cereales como el centeno, el tranquillón y la escanda eran sustituidos progresivamente por el trigo. La patata, de poca importancia a finales del siglo xviı, se convirtió en un producto fundamental en la dieta un siglo más tarde. El aceite de oliva se benefició de una caída en los costes del transporte, en la segunda mitad del siglo, y su importancia en la alimentación aumentó, aunque para los agricultores esta ventaja fue contrarrestada, en parte, por el desplazamiento de este aceite en los usos industriales y en el alumbrado. En contraste: el consumo de vino en España reaccionó a los altos precios de la gran demanda

${ }^{61}$ Prados (1988), pp. 103-104.

${ }^{62}$ Estadística(s) de comercio exterior. Una cifra bastante mayor del consumo de chocolate en 1900 (6,2 kilos por habitante y año), en Nadal (1987), p. 37.

${ }^{\circ 3}$ García Fernández (1975). 
en Francia y probablemente cayó o se estancó, mientras que la demanda de otras bebidas alcohólicąs.. aue utilizaban alcoholes imaortąidos...aumentó ${ }^{\text {th }}$.

En general, aunque hubo cambios en la dieta durante el siglo XIX, nuestra cifra de consumo de aproximadamente 2.100 calorias en 1900 ( 2.500 brutas) probablemente no fue muy diferente a la cifra en 1800, por tres razones. Primera, los cálculos de los coetáneos no muestran un aumento en el consumo de cereales durante el siglo. Utilizando los mismos métodos, las cifras de producción del trigo y del centeno en el Censo de Frutos proporcionó un consumo de 950 calorías/habitante/día, en contraste con las 1.131 calorías en 1900, aunque la cifra de consumo de 6 fanegas de cereales del Censo arroja una cifra cercana a las 1.725 calorías ${ }^{65}$. Segunda, una cuantía mucho menor de 2.100 calorías/día no sería compatible con una economía en la que un alto porcentaje de la población trabaja en empleos manuales. Y tercera, la cifra supondría, a corto plazo, caídas importantes en algunos años. Por ejemplo, una disminución de un 20 por 100 en la oferta de alimentación supondría un consumo medio en el país de 1.680 calorías. Por supuesto que el consumo per capita en un país medido en calorías fuese el mismo entre dos fechas no es sinónimo de estancamiento. Al contrario, como hemos visto, ocurrieron cambios en la dieta, y los grandes avances en los sistemas de transportes facilitaron una oferta más estable. En teoría, también puede ocurrir una sustitución de alimentos baratos por alimentos más caros (más carne, menos pan, etc.).

\section{CUADRO 7}

Estimaciones en el crecimiento anual de la agricultura española, 1800-1900

\begin{tabular}{|c|c|c|c|c|c|}
\hline \multirow{2}{*}{$\begin{array}{c}\text { Cambio en el consumo de } \\
\text { calorias/dia/babitante } \\
\text { entre } 1800-1900\end{array}$} & \multicolumn{2}{|c|}{ Calorias netas } & \multicolumn{2}{|c|}{ Calorias netas } & \multirow{2}{*}{$\begin{array}{l}\% \text { anual } \\
\text { cambio en } \\
\text { el producto } \\
\text { agrario }\end{array}$} \\
\hline & 1800 & 1900 & 1800 & 1900 & \\
\hline 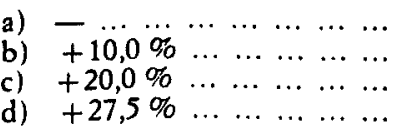 & $\begin{array}{l}2.100 \\
1.909 \\
1.750 \\
1.647\end{array}$ & $\begin{array}{l}2.100 \\
2.100 \\
2.100 \\
2.100\end{array}$ & $\begin{array}{l}2.100 \\
2.100 \\
2.100 \\
2.100\end{array}$ & $\begin{array}{l}2.100 \\
2.310 \\
2.520 \\
2.678\end{array}$ & $\begin{array}{l}0,64 \\
0,76 \\
0,89 \\
1,00\end{array}$ \\
\hline
\end{tabular}

Notas: Véase texto. Población: 0,55 por 100.

Prados de la Escosura: $1800-1890,0,58-0,93$ por $100 ; 1800-1910,0,69-1,10$ por 100 (Prados de la Escosura, 1988, cuadros 3.5). Garrabou-Sanz: 1795-1895, la producción de cereales (volumen), 0,62 por 100 (Garrabou-Sanz, 1985, p. 123).

- Por ejemplo, el precio de una carga de vino en San Pere de Ribes subió desde unas 18,7 pesetas en 1873.75 hasta 36,7 pesetas en 1883.85 . Para el mercado interior de vino, véase Simpson (1986), pp. 16-26.

os Los coeficientes utilizados son los mismos en las dos fechas. 
Sin embargo, como hemos dicho antes, es difícil encontrar datos que apoyen

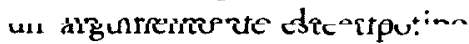

Si se supone una cifra media de 2.100 calorías habitante/día para el siglo xix, la producción a largo plazo cambiaría al mismo ritmo y dirección que la población, corregido por las cifras de importación y exportación de alimentos. Por lo anteriormente expuesto, sería difícil identificar el movimiento de productos individuales dentro del total, y aquí solamente se considera el valor total del producto agrario. El cálculo del Grupo de Estudios de Historia Rural (GEHR) da al sector una cifra de 4.386 millones de pesetas para $1900^{\circ 6}$. Corregido por las cifras del comercio exterior, el consumo de alimentos per capita en el país en aquel año fue de 215,5 pesetas. El consumo en cada decenio ha sido calculado multiplicando esta cifra por la población (Apéndice 2). Para obtener el producto agrario, la cifra de consumo ha sido, naturalmente, corregida por los cambios en el comercio exterior.

Para convertir los precios de 1900 a precios corrientes, se ha utilizado un índice del precio del trigo. Esto no es lo óptimo, pero quizá es mejor que el uso del índice de Sardá; ya que no es una media ponderada, representa solamente un mercado (Barcelona) y contiene sólo los productos de trigo, harina, arroz, aceite, vino, azúcar, café, cacao y algodón.

Los resultados muestran un crecimiento anual de la producción agraria de un 0,64 por 100 , que es superior al de la población $(0,55$ por 100$)$, y que está dentro de los límites obtenidos en los cálculos de Prados de la Escosura $(0,6-1,1 \text { por } 100)^{67}$. Sin embargo, como las dificultades para calcular el producto agrario con este método son muchas, se han hecho otras estimaciones, recogidas en el cuadro 7 , suponiendo un mayor crecimiento en la producción agraria y en el consumo de calorías por habitante ${ }^{68}$. Por ejemplo, si el consumo en 1900 fuera un 10 por 100 mayor que en 1800 , el nivel de crecimiento anual sería de un 0,76 por 100. Para conseguir un crecimiento en la producción agraria de un 1 por 100 anual, hubiera sido necesaria una media de 1.647 calorías brutas en 1800 (con 2.100 en 1900), o 2.678 calorías en 1900 (con 2.100 en 1800 ).

Parece razonable, por tanto, suponer que el producto agrario creció lentamente durante el siglo xIX, con lo que una visión más pesimista del sector, como la de Tortella, es más aceptable que la optimista de Prados. Un crecimiento anual durante el siglo de entre, por ejemplo, 0,64 y 0,76 por 100 ,

1900=1897-1901. GEHR (1983), Apéndice 2.

${ }^{67}$ Por los fuertes movimientos en los precios, la cifra de 0,64 ha sido obtenida utilizando los años $1815-19$ y 1900.

on Entre otras, la exclusión de las plantas silvestres y la caza. Como durante el siglo la superficie cultivada aumentó, la oferta de estos alimentos quizás se redujo. Si éste fue el caso, sería necesario suponer un mayor aumento en el consumo de alimentos agrarios como compensación, para mantener el consumo total de calorías constante. 
significaría pocos cambios en la productividad de la tierra y de la mano de obra ${ }^{69}$. Pero, en contraste con esta visión de «fracaso» del sector, existen tres avances muy importantes en la época. Primero, la agricultura española alimentó en gran medida 18,6 millones de personas en 1900, en contraste de los 10,5 millones en 1800. Además, en la segunda fecha, las exportaciones desempeñaron un papel más importante que en la primera. Segundo, si el crecimiento del producto agrario fue relativamente modesto durante el siglo, la parte comercializada creció con mucha más rapidez. Las mejoras en los sistemas de comunicaciones y los cambios en las restricciones legales permitieron una mayor integración del mercado y una mayor concentración de la población en las ciudades. Si España tenía solamente 34 ciudades de nás de 10.000 habitantes en 1800, tres menos que en 1600, la cifra llegó hasta 174 en 1890, y el número de habitantes en estas ciudades aumentó de 1,17 millones a 4,71 millones, lo que implica un crecimiento anual de 1,56 por $100{ }^{70}$. Consecuencia del mayor nivel de urbanización y las exportaciones fue el uso de una cantidad de recursos cada vez mayor en el almacenamiento, el transporte, y las actividades comerciales para permitir la venta de los excedentes del campo ${ }^{71}$. Por último, al lado de estos cambios ocurrieron otros en las industrias alimenticias que permitieron una mejora en la calidad de los productos ${ }^{72}$.

\section{CONCLUSION}

Este trabajo ha intentado mostrar que no existen fuentes fiables para determinar los cambios a largo plazo de la producción agraria del siglo xix. Aunque es posible que los archivos puedan facilitar más datos en el futuro, las dificultades que encontraban los coetáneos para construir un cálculo de producción desconociendo la superficie cultivada va a arrojar dudas sobre sus cifras. Por esta razón parece necesario buscar métodos alternativos para determinar la producción durante aquel siglo. A este respecto, el estudio del consumo arroja alguna luz sobre el asunto. En los últimos años del siglo XIX y primeros del $\mathrm{xx}$, el bajo consumo de carne y otros alimentos de lujo o semilujo, y una cifra relativamente baja de calorías/día/habitante, no permitió una

* Hay grandes dificultades en determinar los cambios en la población activa en el siglo Xix, como ha apuntado Pérez Moreda (1985), pp. 56-59. En general, la interpretación ha sido un estancamiento en el porcentaje en la agricultura durante todo el siglo. Sin embargo, la experiencia de muchos países en Europa en esta época fue una reducción. Véase Prados (1988), cap. 1.

${ }_{70}$ De Vries (1984), cuadros $3.1,3.2$ y 3.8 .

"Hayami y Ruttan (1985), pp. 29.30.

72 Nadal (1987). 
mejora significativa en la dieta de la población durante el siglo. Entonces podemos tener aproximadamente una idea de las fluctuaciones en la producción por los cambios en la población y en el comercio exterior. En este caso un aumento anual de 0,64 ó 0,76 por 100 durante el siglo XIX, poco más rápido que el crecimiento en la población, supondría un estancamiento en la productividad de la mano de obra, en contraste con la visión más optimista de Leandro Prados, que da un crecimiento anual de la productividad de un 0,4 por $100^{73}$. La falta de transformaciones en la mecanización de las tareas agrarias, y la probable reducción en la oferta de abonos orgánicos, supondría que las posibilidades de aumentar la productividad solamente ocurrirían por la reducción en la población activa en la agricultura, o por la sustitución de las cosechas de relativamente bajo valor por otros más altos ${ }^{74}$. Los cambios significativos en la productividad de la tierra y de la mano de obra tendrían que esperar hasta el siglo $\mathrm{xx}$.

${ }^{3}$ Prados (1988), p. 114.

" El olivo y la vid utilizaron en general más mano de obra durante el año que la rotación cereal-leguminosa. En 1900, la superficie combinada de estos dos productos fue solamente el 22 por 100 de los cereales y leguminosas en rotación (GEHR, 1983, Apéndice 1), y su ritmo de crecimiento, un modesto 0,54 por 100 entre 1860 y 1900 (GEHR, 1983, y Garrabou y Sanz, 1985, cuadro 16). 


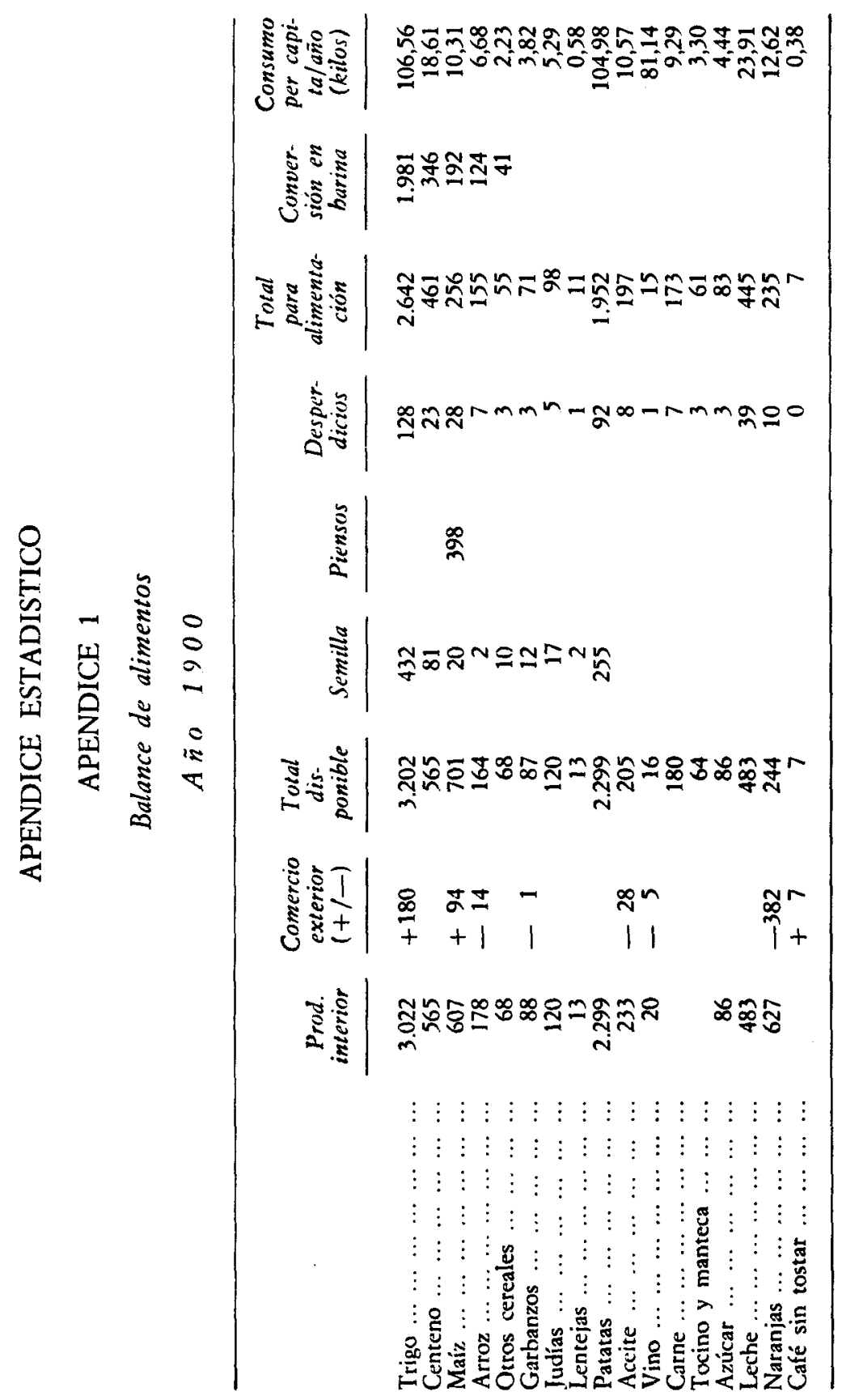




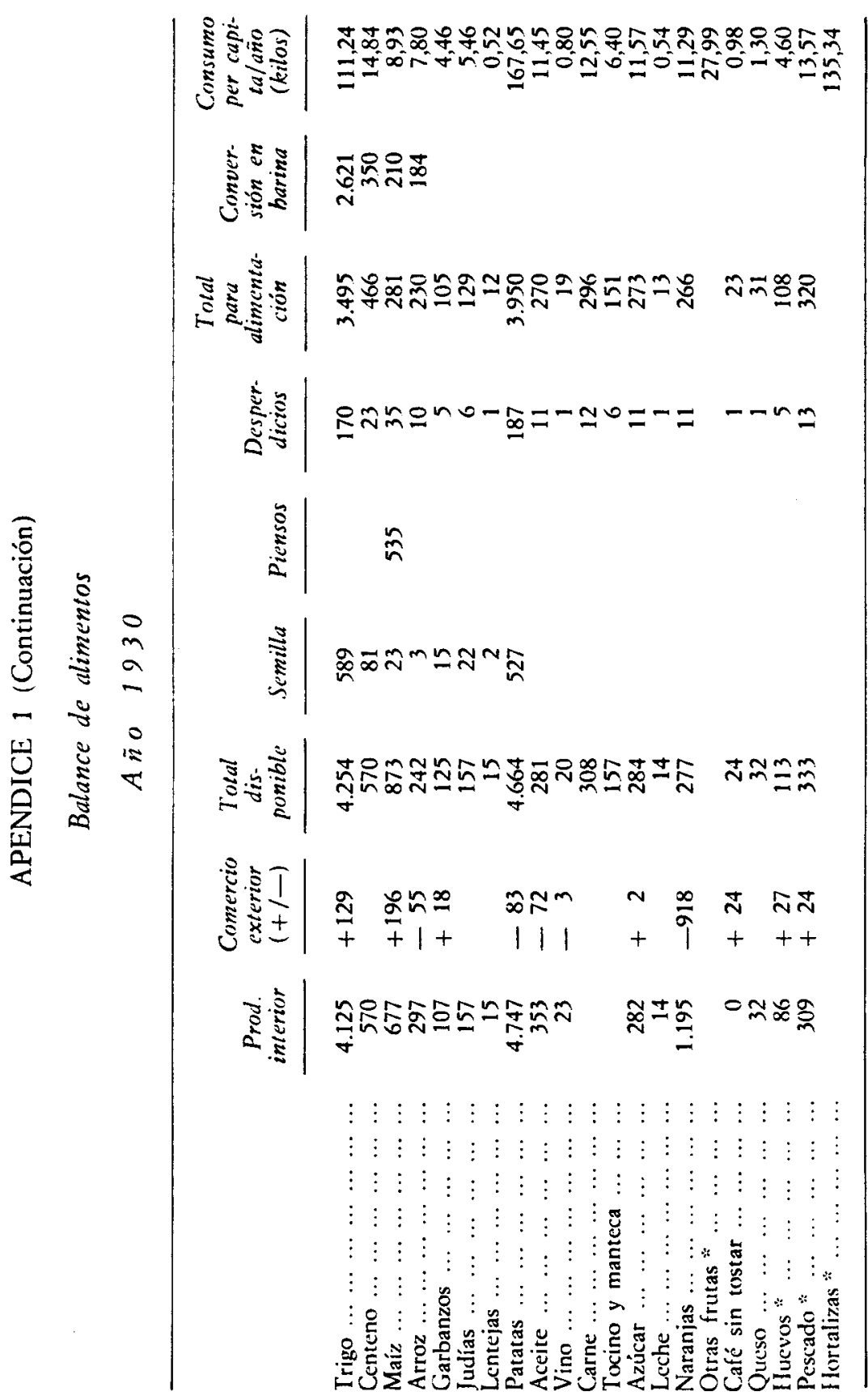




\section{APENDICE 1 (Continuación)}

\section{Balance de alimentos}

Notas: Cifras en miles de toneladas y millones de hectolitros.

Coeficientes: Semillas: trigo, centeno, «otros cereales» y leguminosas, 1/7; maíz, I/30; arroz, 1/90, y patatas, 1/9. Piensos - maíz-: la importación más la mitad de la producción doméstica. Desperdicios: 4 por 100 del total disponible $(8$ por 100 en el caso de la leche). Moliendu: trigo, centeno, "otros cereales" y maíz, 75 por 100 ; arroz, 80 por 100 .

El año 1900 corresponde a los años 1897-1901, y el año 1930, a 1929-1933. Las fuentes y métodos para estimar la producción son igual que los usados por GEHR (1983). pp. 185.252, excepto en el caso de los datos señalados con un arterisco ("), que han sido calculados a partir de Barbancho (1960), pp. 271-367.

El consumo de carne en 1930 ha sido calculado utilizando las cifras de animales en vivo del Ministerio de Agricultura (Anuario de 1930) y utilizando los coeficientes de carne en canal y carne útil, tocino y manteca de Sanz Egaña (1948), pp. 150-151 y 394.395. Para 1900, la Comisión Extraparlamentaria del Impuesto de Consumo (1906), vol. 1, cuadros 51-53, tiene una estimación de carne en canal, y los coeficientes de Sanz Egaña han sido utilizados para convertirlos en productos de consumo. Las vísceras han sido calculadas utilizando los coeficientes de Barbancho (1960), pp. 303-305.

Las cifras de leche en 1930 son del Ministerio de Agricultura (Anuario 1931), donde a cada vaca da una media de 1.046 litros/año. Para 1900, esta cifra ha sido reducida en un 20 por 100 ( 837 litros/año en vez de 1.046). En su cálculo de 1877, Javier de Bona utilizó la media en Francia, 730 litros/año. Bona (1879), p. 390 .

Las cifras de azúcar se refieren a los años 1900 y 1901 . Estos años y 1929.33 proceden de Jiménez Blanco (1986), pp. 314-315. 


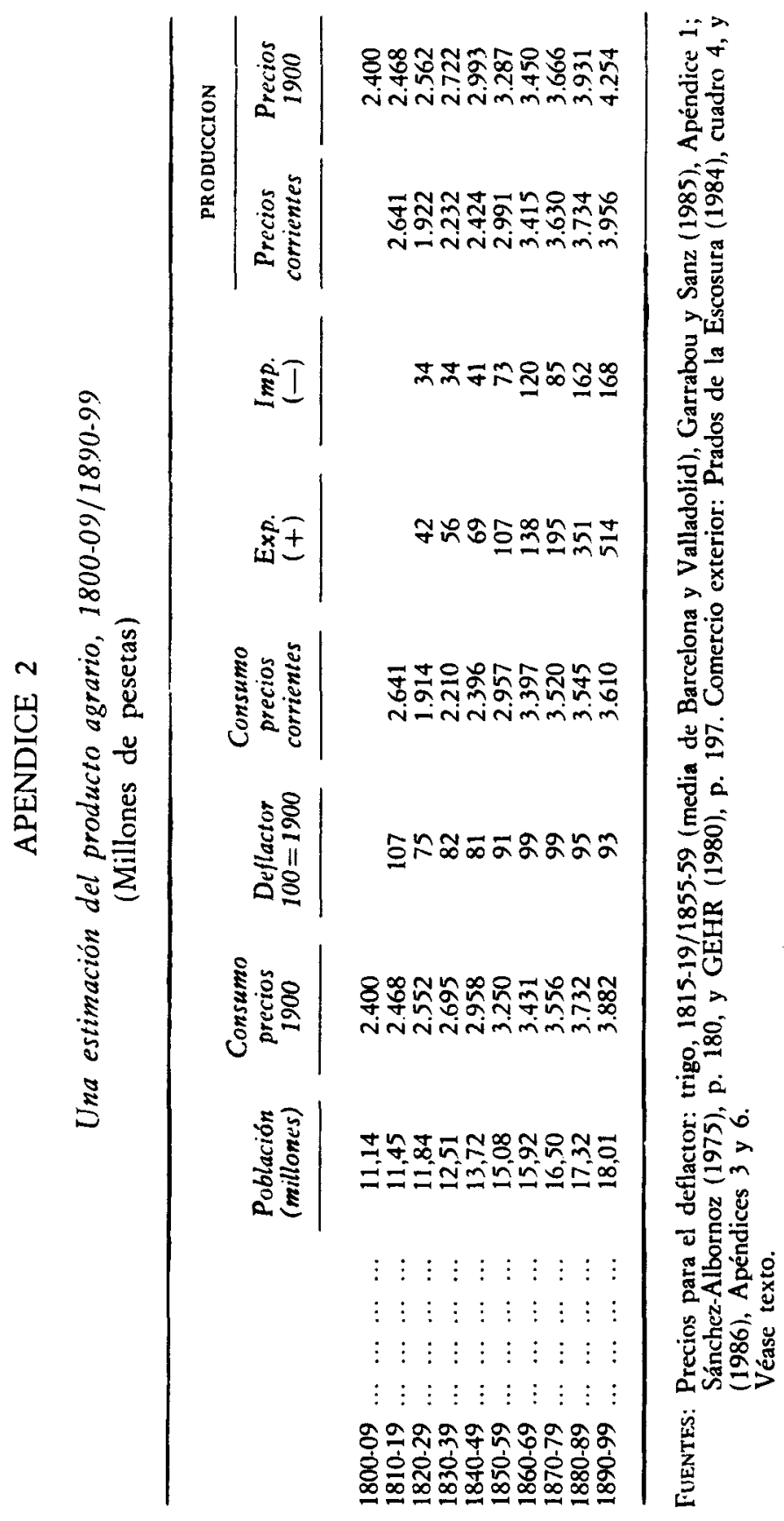




\section{BIBLIOGRAFIA}

ANLs, G. (1966): "Las fluctuaciones de los precios del trigo, cebada y del aceite en España (1788-1808): un contraste regional». Moneda y Crédito, núm. 97, pp. 69-102.

- (1970): Las crisis agrarias en la España moderna, Madrid.

- (1988): Economía y Sociedad en la Asturias del Antiguo Régimen, Barcelona.

ANTÚNEZ, L. (1887): Informe sobre la crisis actual de las industrias pecuaria y vitivinicola emitido por una Junta de Notables convocada al efecto y presidida por el..., Barcelona.

ARrazola, F. (1896): Informe sobre la producción, comercio y consumo de trigo en España, Madrid.

Asso, Ignacio de (1798): Historia de la economia política de Aragón, Zaragoza.

Barbancho, A. G. (1960): "Análisis de la alimentación española", Anales de Economia, vol. XVIII, pp. $73-119$ y $271-367$.

- (1961): «Un método para determinar el salario mínimo vital y su aplicación a España», Estadistica Española, núm. 13, pp. 56-72.

Boletín Semanal de Estadística y Mercados, núms. 310 y 323, 1897, y núm. 418, 1899.

Bona, J. de (1879): «Producto de la leche de vacas», Gaceta Agricola (GAMFM), núm. 3.

Bruneton-Governatori (1984): "Alimentation et idéologie: la châtaigneen France», $A n$ nales ESC, núm. 39, pp. 1161-1189.

Calomarde, T. F. de (1800): Discurso económico-politico leido en la Real Sociedad aragonesa, y aprobado por la misma, en el que se demuestra la cantidad de trigo y demas granos y frumenticios que en cada año de este ultimo quinquenio se ba cogido en el reino de aragón, la pobiación general de esta provincia, su consumo y medios de extraer el sobrante y de introducir lo necesario; poniendose al fin las reglas más principales para fomentar su agricultura, Madrid.

Canga Argüelles, J. (1833): Diccionario de Hacienda, 2 vols. Madrid.

Comisión Extraparlamentaria del Impuesto de Consumo (1906): Documentos y trabajos de la Comisión, 4 vols., Madrid.

Conard, P. (1974): "Problemas de la evaluación del coste de vida en España», Revista de Trabajo, núm. 48, pp. 297-316.

CRAFTS, N. F. R. (1976): "English Economic growth in the eighteenth century: a reexamination of Dean and Cole's estimates", Economic History Review, XXIX, pp. 226-235.

Crisis Agrícola y Pecuaria, La (1887), 7 vols., Madrid.

Dirección General de Agricultura, Industria y Comercio (1891): La Estadistica so. bre el cultivo del cereal y de leguminosos asociados en España, 3 vols. Madrid.

Espadas Burgos, M. (1968): “El hambre de 1812 en Madrid», Hispania, núm. 110, pp. 594-623.

Fernández García, A. (1971): El abastecimiento de Madrid en el reinado de Isabel II, Madrid.

Fontana Lázaro, J. (1967): “El "Censo de frutos y manufacturas" de 1799: un análisis crítico», Moneda y Crédito, núm. 101, pp. 54-89.

- (1978): «La crisis agraria de comienzos del siglo xIx y sus repercusiones en España», Hacienda Pública Española, núm. 55, pp. 177-190.

Garcia Fernández, J. (1975): Organización del espacio y economia rural en la España Atlánticu, Madrid.

García SANZ, A. (1978): "La agonía de la Mesta y el hundimiento de las exportaciones laneras: un capítulo de la crisis económica del Ántiguo Régimen en España», Agricultura y Sociedad, núm. 6, pp. 283-356.

Garrabou, R. (1980): «Un testimonio de la crisis de subsistencia de 1856.57: el expediente de la Dirección General de Comercio», Agricultura y Sociedad, núm. 14, pp. $269-294$.

Garrabou, R., y Sanz, J. (1985): «Introducción» a Garrabou, R., y Sanz, J.: Historia agraria de la España contemporánea. 2. Expansión y crisis (1850-1900), Barcelona. 
Grupo de Estudios de Historia Rural (GEHR) (1978-79): «Contribución al análisi: histórico de la ganadería española, 1865-1929», Agricultura y Sociedad, VIII, pp. 129. 182 ; X, pp. 105-169.

- (1980): Los precios del trigo y la cebada en España, 1891-1907, Madrid.

- (1983): «Notas sobre la producción agraria española, 1891-1931», Revista DE Historia ECONómICA, núm. 2, pp. 185-252.

GrEIG, D. (1982): The Dynamics of Agricultural Change, Londres.

Hayami, Y., y Ruttan, V. W. (1985): Agricultural Development, Baltimore.

JACKSON, R. V. (1983): "Growth and Deceleration in English Agriculture, 1660-1740", Economic History Review, XXXVIII, pp. 333-351.

JimÉnEz BlanCo, J. I. (1986): «La remolacha y los problemas de la industria azucarera en España, 1880-1914», en Garrabou, Barciela y Jiménez Blanco, Historia agraria de la España contemporánea, vol. 3, pp. 280-316.

LAIns, P. (1987): Indice da Produção Agrícola em Portugal, 1845-1913, manuscrito inédito.

LLOPIS AGELÁN, E. (1982): «Las explotaciones trashumantes en el siglo XVIII y primera mitad del xix: la cabaña del Monasterio de Guadalupe, 1709-1835», en ANES, G. (ed.), La economia española al final del Antiguo Régimen. 1. Agricultura, pp. 2-101.

Lipton, M. (1983): Poverty, Undernutrition, and Hunger, World Bank Working Papers, núm. 597.

Livi-Bacci, M. (1988): Ensayo sobre la bistoria demogrática europea. Población y alimentación en Europa, Madrid.

López y Peñalver (1812): Reflexiones sobre el precio del trigo, Madrid.

MALUquer de Motes, J. (1987): «De la crisis colonial a la guerra europea: veinte años de economía españolam, en Nadal, Carreras y Sudrì̀, La economia española en el siglo XX: Una perspectiva bistórica, Barcelona, pp. 62-104.

Ministerio de Agricultura (1926-36): Anuarios estadisticos de la producción agricola, años 1925.35, Madrid.

Mitchell, B. R., y Deane, P. (1971): Abstract of British Historical Estatistics, Cambridge.

MoKYR, J. (1988): «Economic, History, and Human Biology», Economic Development and Cultural Change, vol. 36, núm. 3, pp. 559-564.

Moreau de Jonnes, A. (1835): Estadistica de España, Valencia.

NADAL, J. (1975): El fracaso de la Revolución industrial en España, 1814-1913, Barcelona.

- (1987): «La industria fabril española en 1900. Una aproximación», en NADAL, CARRERAs y SUDRIÀ: La economía española en el siglo XX: Una perspectiva bistórica, Barcelona, pp. 23-61.

O'BRIEN, P. (1985): «Agriculture and the home market for English industry, 1660-1820», English History Review, núm. 4, pp. 773-800.

ODdy, D. J. (1976): "A Nutritional Analysis of Historical Evidence: The Working Class Diet, 1880-1914", en ODDY y Miller (eds.): The Making of the British Diet, Londres, pp. 214-231.

Pérez Moreda, V. (1985): «La modernización demográfica, 1800-1930. Sus limitaciones y cronología», en N. SánCHEZ-Albornoz (ed.): La modernización económica de España, 1830-1930, Madrid.

- (1985): «Consum deficitari, fam i crisis demogràfiques a l'Espanya dels segles XvI-xIX», Estudis d'Història Agrària, núm. 5, pp. 7-24.

Prados de la Escosura, L. (1984): «La evolución del comercio exterior, 1790-1929», Papeles de Economia Española, núm. 20, pp. 133-154.

- (1986): "Una serie anual del comercio exterior español (1821-1913)», Revista DE HisTORIA ECONÓmæiCa, núm. 1, pp. 103-150.

- (1988): De imperio a nación. Crecimiento y atraso económico en España (1780-1930), Madrid.

Polo y Catalina (1803): Censo de frutos y manufacturas de España e islas adyacentes, Madrid, sin paginación.

Reformas Sociales, Intormación y escrita practicada en virtud de la Real Orden de 5 de diciembre de 1883, Madrid, 1839, tomo I. 
SÁnChez-Albornoz, N. (1975): Los precios agricolas durante la segunda mitad del siglo $X I X$, Madrid.

- (1977): España hace un siglo: una economia dual, Madrid.

SANZ, J. (1981): "Notas introductorias al libro de Eduardo de la Sotilla», Agricultura y Sociedad, 1981, núm. 18, pp. 303-330.

SANZ BREMÓN, M. (1979): «Contestación al interrogatorio publicado por la Dirección General de Agricultura con fecha 20 de enero de 1881\%, Estudis de Història Agrària. núm. 2, pp. 254-288.

Sanz Egaña, C. (1948): Enciclopedia de la Carne, Madrid.

SEN, A. (1982): Poverty and Famines. An Essay on Entitlement and Deprivation, Oxford.

Shammas, C. (1984): «The Eighteenth Century English Diet and Economic Change», Explorations in Economic History, 21/3, pp. 254-269.

SIMPSON, J. (1985): «El consumo y producción de cereales panificables en el siglo XIX», Memoria Banco de España, Madrid.

- (1986): «La Producción Agraria en 1886-90: un enfoque de la agricultura española del siglo XIX», Memoria Banco de España, Madrid.

- (1988): «Technical Change, Labour Absorption and Living Standards in Andalucía, 1886-1936m, Documento de Trabajo 8810, Universidad Complutense de Madrid.

SMIL, V. (1986): «Food Production and Quality of Diet in China», Population and Development Review, 12, pp. 32-40.

Sotilla, E. de la (1911): «Producción y riqueza agrícola de España en el último decenio del siglo xIx y primero del xx», Boletín de Agricultura Técnica y Económica, año V; reimpreso en Agricultura y Sociedad, núm. 18, 1981, pp. 331-409.

Srinivasan, T. N. (1981): «Malnutrition. Some Measurement and Policy Issues», Journal of Development Economics, núm. 8, pp. 3-19.

SupPle, B. E. (1981): «Income and Demand», en Floud y McCloskey (eds.): The Economic History of Britain since 1700 , vol. 2.

Tilly, L. A. (1985): «Food Entitlement, Famine, and Conflict», en Hunger and History. The Impact of Changing Food Production and Consumption Patterns on Society, Cambridge.

Tortella Casares, G. (1985): «Producción y productividad agraria, 1830-1930», en N. SánChez-Albornoz (ed.): La modernización económica de España, 1830-1930, Madrid.

- (s. f.): «Comentarios a "La Producción Agrícola en España en el siglo xix", de Leandro Prados» (inédito).

Toutain, J. C.: «La consommation alimentaire en France de 1789 à 1964», Economies 't Sociétés, Cahiers de l'ISEA, Ginebra, 1971.

VRIES, J. de (1984): European Urbanization 1500-1800, Londres.

Zambrana Pineda, J. F. (1987): Crisis y modernización del olivar español, 1870-1930, Madrid.

ZapaTA, S. (1986): La producción agraria de Extremadura y Andalucia occidental, 18751935 (tesis doctoral), Editorial de la Universidad Complutense de Madrid, 53/86, 2 vols. 